Bio-grafia: Escritos sobre la Biologia y su Enseñanza Vol. 4 No. 6 ISSN 2027-1034. Primer semestre de 2011, Bogotá, Colombia, p. p. 51-87

\title{
LA INVESTIGACIÓN EN TORNO A LA CONCEPCIÓN DE VIDA SILVESTRE: UNA APROXIMACIÓN AL ESTADO DEL ARTE EN EL CONTEXTO EDUCATIVO.
}

THE INVESTIGATION AROUND THE CONCEPTION OF WILDLIFE: AN APPROACH TO THE STATE OF THE ART IN THE EDUCATIONAL CONTEXT.

Por: Luis Juan Rubiano O. ${ }^{1}$

\begin{tabular}{|l|}
\hline Recibido: 15-03-2011 \\
\hline Aceptado: 03-06-2011 \\
\hline
\end{tabular}

\section{Resumen}

Se hace una revisión sobre el origen de la concepción de vida silvestre, rastreando su significado desde el siglo XIV hasta el presente. Aunque existen en Inglaterra referencias muy antiguas sobre la concepción de vida silvestre, es en Estados Unidos donde nace y evoluciona dicho término. Al comparar las concepciones de la vida silvestre en los Estados Unidos respecto a los países latinoamericanos, se evidencia la enorme importancia cultural, educativa, política y social dada a tales concepciones en el continente norteamericano en contraste con Latinoamérica, particularmente Colombia, en donde no se dan tales manifestaciones. Igualmente, la historia de la educación e investigación en educación sobre la vida silvestre en los Estados Unidos revela una notoria inserción de esta temática tanto en los textos divulgativos (educación no formal) como en la literatura científica y en los currículos de educación básica y universitaria. En dicho país es posible conjeturar un cambio evolutivo en la concepción de vida silvestre que, de acuerdo con nuestra investigación, se inicia a finales del siglo XIX con un significado de fauna de caza deportiva y culmina, hacia la década de 1970 con la inclusión de todos los reinos de la naturaleza así como su hábitat e interrelaciones. En nuestro país, y en general para Suramérica, es muy escasa la literatura especializada sobre vida silvestre, no existiendo facultades o carreras con dicha temática a pesar de la enorme biodiversidad de este continente. Algunas de las razones aducidas por el autor, que explican esta situación, son la influencia de la visión taxonómica de la naturaleza, privilegiada en Colombia por la Expedición Botánica, y la dificultad para incorporar la educación ambiental en el contexto académico universitario. Se concluye igualmente la escasa investigación en vida silvestre y el potencial que existe para desarrollarla en el campo de las ciencias naturales y sociales, particularmente en el campo de la educación. Finalmente se destaca la importancia de la vida silvestre como un recurso de bienestar y supervivencia humana así como la necesidad de concebirla desde un punto de vista ético y de derechos.

Palabras clave: Vida silvestre, concepciones, educación en vida silvestre, estado del arte

\section{Summary}

A review is made on the origin of the conception of wildlife, tracking its meaning

${ }^{1}$ Estudiante de Doctorado Universidad Distrital Francisco José de Caldas. Profesor Departamento de Biología Universidad Nacional de Colombia. Correo: luisrubiano@yahoo.com 
from the XIV century until the present. Although in England exist very old references on the conception of wildlife, it is in United States where it was born and evolves this term.

When comparing the conceptions of the wild life in the United States regarding the Latin American countries, the enormous cultural, educational, politics and social importance, is evidenced to such conceptions in the North American continent in contrast with Latin America, particularly Colombia where such manifestations don't take place. Equally, the history of the education and investigation in education about the wildlife in the United States reveal a notorious insert of this thematic so much in the popularization texts (non formal education) as in the scientific literature and in the curricula of basic and university education. In USA it is possible to surmise an evolutionary change in the conception of wildlife that, in accordance with our investigation, it began at the end of the XIX century with a meaning of fauna of sport hunt (game species) and it culminated, toward the decade of 1970 with the inclusion of all kingdom of the nature as well as its habitat and interrelations. In our country, and in general for South America, it is very scarce the specialized literature about wildlife, not existing faculties or careers with this thematic in spite of the enormous biodiversity of this continent. Some of the reasons adduced by the author that explain this situation are the influence of nature taxonomic vision, privileged in Colombia by the Botanical Expedition, and the difficulty to incorporate the environmental education in the university academic context. Likewise, it concludes the scarce investigation in wild life and the potential that it exists to develop it in the field of the natural and social sciences, particularly in the field of the education. Finally we emphasize the importance of the wildlife as a resource of well-being and human survival as well as the necessity to conceive it from an ethical and rights point of view.

Words key: Wildlife, conceptions, wildlife education, state of the art

\section{INTRODUCCIÓN}

Durante los últimos 50 años hemos asistido a uno de los episodios de extinción de especies silvestres más importantes del mundo. Según los últimos reportes de la UICN (2008), de las 44.837 especies registradas en sus Listas Rojas, 804 ya se han extinguido, cifra que ascendería a 1159 si se tienen en cuenta las 290 especies en peligro crítico de extinción. Un $38 \%$ del total de la lista (19.728 especies) se reportan además como amenazadas de extinción (UICN, 2008). En Colombia, para el año 1999, el Instituto Von Humbolt reportaba 351 especies de macrofauna en peligro de extinción, distribuidas en 132 especies de mamíferos, 163 especies de aves, 31 de reptiles y 25 de anfibios (Instituto de Investigación de Recursos Biológicos Alexander Von Humboldt, 1999). Para el 2002 esta cifra había ascendido a 385 especies, con tendencia hacia el aumento (Ministerio del Medio Ambiente, 2002). Este fenómeno de pérdida de vida silvestre es tan descomunal que podría catalogarse entre los seis eventos de mayor extinción masiva en la historia del planeta (Glavin, 2007).

Muchos son los motivos que se pueden exponer para esta catástrofe: la pérdida de hábitat, ocasionada principalmente por la tala extensiva de bosques, la caza comercial, la ampliación de la frontera agrícola, el cambio climático y aspectos relacionados con la educación. 
El término "vida silvestre" tiene varias connotaciones según el continente y/o país de que se trate. Esta heterogeneidad de concepciones es de gran relevancia en la toma de decisiones políticas y educativas pues dependiendo de ellas es posible favorecer o perjudicar la preservación de la vida silvestre. Visto de esta manera, el fenómeno de la extinción de especies estaría fuertemente ligado al desconocimiento del significado y de la importancia de la vida silvestre, bien sea que ésta se tome como un componente independiente del hombre o como un elemento esencial e imprescindible para su supervivencia (Van Dyke, 2003).

El presente artículo pretende dar respuesta a varias preguntas de importancia crucial respecto al significado de vida silvestre: la manera como se ha interpretado este concepto en diferentes contextos históricos y geográficos, particularmente del continente americano; su inserción en el sistema educativo norteamericano (el de mayor tradición en estos estudios); la manera como se ha venido desarrollando la investigación en educación sobre vida silvestre así como su abordaje en el ámbito legislativo y educativo colombiano; y finalmente su importancia, desde varias perspectivas, para el bienestar humano así como su concepción ética y de derechos. Esta revisión hace parte de un estudio adelantado por el autor como proyecto de tesis del Doctorado Interinstitucional en Educación de la Universidad Distrital Francisco José de Caldas.

\section{METODOLOGIA}

La investigación en torno a las concepciones de vida silvestre tuvo en cuenta la consulta documental de cuatro tipos de información, dentro de un período muy amplio (siglos XIV a XXI). Esta información fue filtrada y sistematizada de acuerdo a criterios indicados más adelante. En general se siguió el siguiente procedimiento: 1) búsqueda del concepto de vida silvestre en diccionarios de español (V.gr. Diccionario Ilustrado Océano de la Lengua Española, 1997, Gran diccionario de la lengua española Larousse, 2009) y de inglés (Diccionario Thesaurus Ingles-Inglés, 2010; Diccionario Oxford Español-Inglés - InglésEspañol, 1994). Esto para tener una percepción sobre la manera en que idiomáticamente se interpreta este concepto, conociendo de antemano que la interpretación es diferente tanto en español como en inglés. 2) Revisión bibliográfica en bibliotecas universitarias: Biblioteca del Doctorado Interinstitucional en Educación de la Universidad Distrital Francisco José de Caldas; Biblioteca Central, Biblioteca de Ciencia y Tecnología y Biblioteca Ernesto Guhl de la Universidad Nacional de Colombia; Biblioteca Central de la Universidad Pedagógica Nacional. 3). Aprovisionamiento y consulta de revistas y libros pertinentes, adquiridos a lo largo de 14 años de dictar la cátedra "Percepción y apreciación de la vida silvestre" en el Departamento de Biología de la Universidad Nacional de Colombia. 4) Revisión en la Web, de artículos y libros científicos cuyos títulos contuvieran las palabras vida silvestre y/o wildlife. Se utilizaron los motores de búsqueda más accesibles y completos: Eric, Biblioteca virtual Miguel de Cervantes Saavedra, Annual Reviews, Jstor, Web of science-science citation index expanded, Web of science-social sciences citation index, Ebrary-elibro (XML Español), Wiley interscience-Wiley Journals, entre otras. 5) El intervalo temporal de la investigación cubrió, de manera muy general, los siglos XIV a XXI. Información original (es decir, no citada por otros autores en textos recientes) se obtuvo a partir de comienzos del siglo XX, por ejemplo, Holden (1906, facsimil 1980), Holden (1905, facsimil 1989) y Hornaday (1913). 6) Se aplicaron varios filtros para restringir la abundante información. Los dos principales fueron: a) descartar los artículos monográficos sobre especies silvestres, 
y b) tener solo en cuenta información proveniente de los Estados Unidos (la más voluminosa), Inglaterra (referente histórico de la concepción de vida silvestre), Canadá y los países suramericanos. 7) La información que se consideró útil para el estudio de las concepciones de la vida silvestre , después de aplicar los filtros, se sistematizó de acuerdo con los siguientes categorías: a) estudios de la vida silvestre con una perspectiva históricaontológica, b) estudios con una perspectiva taxonómica, c) estudios con una perspectiva de Educación Ambiental, d) estudios con una perspectiva de legislación ambiental (manejo y conservación) y e) estudios con una perspectiva de conocimiento escolar ecológico (educación).

\section{RESULTADOS}

\section{EL CONCEPTO DE VIDA SILVESTRE: ORIGEN Y DESARROLLO}

\subsection{Inglaterra: La vida silvestre en las Leyes de Caza}

El termino "vida silvestre" nació y se desarrolló en los Estados Unidos de América a comienzos del siglo $X X$, pero su origen puede rastrearse siglos atrás, en la Inglaterra medieval. Los primeros referentes sobre la vida silvestre (aún no reconocida como tal sino como "game species" o especies de caza deportiva) de esta isla se conocen a través de las antiguas leyes de caza, salvaguardadas en los archivos notariales y bibliotecas del Estado. Se sabe, por ejemplo, que desde 1389 a 1831 la ley inglesa restringió el acceso a la fauna silvestre a través de leyes conocidas como "Actos de Requisito", bajo los cuales solamente personas "capacitadas" podían cazar (Kirby, 1933). El requisito principal de calificación era la propiedad de tierras, aunque la riqueza y profesión de los interesados también contaban en estas primeras licencias. No obstante, las leyes de caza se habían desarrollado independientemente de las leyes sobre propiedad de los bosques siendo éstos los lugares privilegiados para los deportes de la aristocracia, aún cuando sus terrenos no les pertenecieran (Kirby, 1933). Con el tiempo, este método de proporcionar el monopolio de la caza deportiva a una clase social tuvo altibajos y en algunos períodos franca decadencia.

El significado de vida silvestre en estas leyes era muy restringido ya que se refería principalmente a animales (mamíferos y aves) de caza deportiva (Luek, 1989). Sin embargo, ya se hacía la distinción entre lo que actualmente, aunque de manera incompleta, entendemos como fauna silvestre y lo que también conocemos como fauna domesticada. Así, durante el siglo XVIII, los derechos de propiedad distinguían dos clases de animales: 1) De naturaleza doméstica (Domitae naturae) que eran mansos y domésticos como el ganado vacuno, ovejas, y aves comestibles, y 2) De naturaleza salvaje (Ferae naturae), como venados, perdices y lobos (Blackstone [1765-69], 1971). Los derechos de propiedad y responsabilidad de las personas sobre los animales domésticos se conservaban, incluso cuando los animales se apartaban de los terrenos del propietario al contrario de los derechos sobre las "ferae naturae" que solo regían mientras el animal estuviera en predios del propietario de la tierra o el animal era muerto por este. Si el animal lograba huir, se perdía el derecho de propiedad que podía ser adquirido por otra persona. En la práctica, los derechos de propiedad sobre la fauna silvestre se otorgaban únicamente a los terratenientes (Blackstone [1765-69], 1971). 
El primer estatuto sobre caza de "fauna silvestre" en Inglaterra fue publicado en I390, cuando se estableció la prohibición de tener perros de cacería y de matar venados, liebres, conejos y otros especimenes de "fauna silvestre" a menos que se pagara un impuesto elevado, que por lo general solo era posible para las clases altas (Kirby, 1933).

La ley de I390 dio lugar a otra serie de leyes parlamentarias dirigida a revisar, reforzar y redefinir la caza deportiva. En ellas se legislaba sobre la caza furtiva, temporadas de caza y venta de piezas silvestres. Dichas reformas culminaron en I67I con una medida que moldeó la ley básica del sistema de caza por más de siglo y medio (Kirby, 1933). Según esta ley, la cacería fue prohibida a personas que no pertenecieran a alguna de estas cuatro categorías: 1) personas que tuvieran tierras o viviendas de su propiedad o de sus cónyuges y que generaran ganancias por arriba de 100 libras al año; 2) aparceros o arrendatarios con contratos mínimos de 100 años; 3) aquellas personas denominadas con el apelativo de "don" $\mathrm{u}$ otro apelativo de dignidad (Kirby, 1933, pp. 241); y 4) propietarios con franquicias. Un rasgo importante de esta ley era la autorización legal que se les dio a los guardias de caza (guardabosques) para confiscar todos los implementos de caza (armas, perros, redes, etc.) de los cazadores furtivos.

Hacia 1750 aparecen las primeras asociaciones independientes de protección de las especies de caza silvestres y en 1752 se crea la primera Sociedad Nacional ("The Society of Noblemen and Gentlemen for the Preservation of the Game") para la preservación de las especies de caza deportiva. En 1785, por ejemplo, ya era necesario un certificado de permiso para la caza legal. Las sanciones impuestas sobre aquellos que infringían las leyes de caza eran por lo general muy severas, por ej. la pena de muerte para los cazadores furtivos (Lueck, 1989).

A pesar de esto, el siglo XIX irrumpe con un renovado afán por la cacería, estimulado por los valores tradicionales de la clase privilegiada que consideraba esta actividad como "la más sagrada entre todas las demás". Según expresiones de la época, la cacería era un deporte de reyes "to be followed only by a superior order of men" (Kirbi, 1933, pp. 243). Por presión de los terratenientes, los estatutos de calificación se abolieron en 1831, y los dueños de la tierra adquirieron nuevamente la propiedad de la vida silvestre.

Con tal presión, Inglaterra se vio abocada a una disminución alarmante de la fauna silvestre recurriendo entonces a su importación desde Francia (Kirbi, op.cit.). Por la misma época (1766), se da inicio a las técnicas de cría y preservación, como recurso suplementario para mantener una reserva de caza para la aristocracia. Actualmente los propietarios de la tierra continúan controlando la legislación sobre la fauna y la flora, conservando, como en el pasado, los privilegios para caza de vida silvestre en terrenos de su propiedad (Lueck 1989).

\subsection{Estados Unidos: La vida silvestre en el contexto de la Conservación}

El término binominal "wild life", tal como lo conocemos ahora en español "vida silvestre", es de origen reciente, probablemente hacia finales del siglo XIX, reportándose oficialmente en Norteamérica con la publicación en 1913 del libro "Our Vanishing Wild Life: Its Extermination and Preservation (Nuestra vida silvestre en desaparición: su exterminio y preservación) de William Hornaday (Hornaday, 1913). Esta publicación es de gran importancia por varias razones: 1 Aunque el autor no hace explícito qué se entiende por "wild life" (lo cual indica que probablemente, ya se utilizaba el término), el uso de éste, dentro del texto, parece corresponder a dos significados: "fauna salvaje" , ("The American bison is saved from being wholly extinct as a wild animal by the remnant of about 300 head in 
northern Athabasca, and 49 head in the Yellowstone Park"- Hornaday, 1913, pp 19-; "There are circumstances under which the killing of a wild animal may be so wanton, so revolting and so utterly reprehensible that the act may justly be classed as murder" -Hornaday, 1913 pp. 26-; "There is on this earth not one wild-animal species-mammal, bird or reptile-that can long withstand exploitation for commercial purposes" -Hornaday, 1913 pp. 142-) y también "especies salvajes de caza" ("in any camp of sheep men, cattle men, lumbermen, miners, railway laborers or excavators to own or use a rifle in hunting wild game"- Hornaday, 1913 pp. 84-; "Song-bird slaughter is growing and spreading, with the decrease of the game birds" - Hornaday, 1913 pp. 7-; "or permit them to be fed, on the flesh of wild game mammals or birds" - Hornaday, 1913 pp. 84), etc. 2 Está centrado en un único reino, el animal, y no reporta los otros reinos (plantas, hongos, protistas) en sus listas de vida silvestre. $3 \mathrm{Si}$ bien aborda un capítulo sobre insectos, estos no son identificados como vida silvestre, sino que son reportados como plagas de los cultivos, de tal modo que no se plantea su protección. 4 Se adelanta a la clasificación actual del convenio CITES$^{2}$ al reportar especies amenazadas y en peligro de extinción.

El control de las actividades relacionadas con la vida silvestre por parte del Estado se inició en 1896 con la Ley Geer, mediante la cual la Corte Suprema de los Estados Unidos prohibió la exportación de especies de caza, dando a las agencias del Estado la autoridad para regular la caza pesca y trampeo (Lueck, 1989). Dicha ley fue ratificada y ampliada mediante la Ley Lacey, en 1900, la primera pieza fundamental en la política de protección de la vida silvestre en los Estados Unidos. Mediante esta ley se prohíbe el transporte interestatal de fauna silvestre y la importación de especies exóticas a su territorio. Igualmente suscribe un convenio de protección de las aves migratorias con Inglaterra y Canadá (Lueck, op.cit).

Como apoyo a la protección de la vida silvestre, a partir de la ley Lacey se han implementado muchas otras leyes de las cuales destacamos la ley Pittman- Robertson (1937) (U.S. Fish and Wildlife Service, 2010a) que crea un impuesto sobre armas y municiones, la ley Dingell-Johnson (1950) (Owen, 2000), que crea impuesto sobre los equipos de pesca y la Migratory Bird Stamp (1934) (U.S. Fish and Wildlife Service, 2010b) que obliga a adquirir una estampilla de impuesto a los cazadores. Los recursos así obtenidos son entregados a los diferentes Estados para ayuda a los programas de protección de la vida silvestre.

La connotación de vida silvestre como especies de caza, tanto en las leyes como en la literatura científica continúa durante las décadas siguientes, incorporando en algún momento la división entre especies de caza mayor (osos, venados, bisontes) y caza menor (zorros, ardillas, linces, etc.). Hacia la década de los 70's se comienza a dar importancia a las especies no incluidas en estas dos categorías, catalogándolas como "wildlife nongame species" e incorporándolas en los programas de conservación a través de los "Wildlife Nongame Programs" (Crawford, 1976). Es también importante el papel creciente de la universidad en la reivindicación de las especies silvestres y el énfasis que comienza a darse al habitat e interrelaciones ecológicas: "An integrated approach, in which game and nongame species are placed within the perspective of an ecosystem, is essential for developing university

2 Convención sobre el Comercio Internacional de Especies Amenazadas de Fauna y Flora Silvestres. Nacida en 1973, constituye un acuerdo internacional concertado entre los gobiernos. Tiene por finalidad velar por que el comercio internacional de especimenes de animales y plantas silvestres no constituye una amenaza para su supervivencia (http://www.cites.org/esp/disc/what.shtml-) 
programs directed toward nongame wildlife" (Crawford, 1976). En una revisión de artículos publicados desde 2000 en la Wild Life Society (Journals: Advanced Search, 2010), la mayor parte de los títulos comprenden temas ecológicos, por ejemplo, habitats de vida silvestre en relación con herbicidas (Miller y Miller, 2004); restauración de ecosistemas (Baker, 2006), dinámica de la vegetación por herbivoría (Wisdom et al, 2006), apareciendo también estudios relacionados con las creencias y actitudes hacia la vida silvestre (Fulton et al, 2004).

La tendencia después de los 90's ha sido incluir dentro de la vida silvestre a otros organismos: "The term wildlife has been used to refer to species of wild plants and animals (but might not necessarily include organisms such as bacteria, víruses, moulds and other life forms which are neither plant nor animal)" (Spellerberg, 1992, pp. 1).

De acuerdo con lo anterior, podemos resaltar algunos hechos relevantes al comparar las concepciones sobre la vida silvestre y sus políticas de uso y protección tanto en Inglaterra como en los Estados Unidos: En Inglaterra la concepción de vida silvestre tiene como principal referencia las leyes de caza y los correspondientes permisos, vedados a las clases menos favorecidas. En los Estados Unidos una de las primeras referencias (Hornaday, 1913) es un llamado de alerta sobre el exterminio de la vida silvestre, una toma de conciencia y una apología a la conservación, todo dentro de un marco científico y actitudinal. Así mismo, el sentido de las normas sobre restricciones a la cacería en los Estados Unidos se aplica a los cazadores comerciales y no, como en el caso de Inglaterra, a las clases populares. En los Estados Unidos, las políticas de protección de la vida silvestre nacieron de hombres acaudalados que deseaban, sin abandonar la caza deportiva, la conservación del habitat y el paisaje. En Inglaterra, la nobleza, como principal motor de la actividad de caza, no tuvo mayor injerencia en las políticas de protección: todo lo contrario, fue la aristocracia quien redujo a cifras mínimas la diversidad silvestre de la isla. Y quizás la diferencia más importante: mientras las leyes inglesas reconocen que la "propiedad" de la vida silvestre, descansa principalmente en los dueños de tierra (Lueck, 1989), las leyes de los Estados Unidos sostienen que es el Estado y no los dueños de la tierra, quien ejerce el control y las políticas de protección de la vida silvestre.

\subsection{Países Latinoamericanos: Vida Silvestre en el contexto de la Legislación Ambiental}

En los países latinoamericanos, el termino "wild life" de Hornaday (1913) (que luego en los Estados Unidos pasó a wildlife -como palabra única- a partir de las publicaciones de la Wildlife Society en 1937) podría traducirse literalmente como "vida salvaje" o "vida silvestre", frase binominal que no existe en el diccionario español. Si traducimos directamente del Diccionario Thesaurus Ingles-Inglés (2010), wildlife es "all living things (except people) that are undomesticated" ("todas las cosas vivientes, excepto el hombre, que no son domesticadas"), mientras el Diccionario Oxford Inglés-Español (1994) la define como fauna y flora, y también como natural.

En nuestro idioma español la palabra wildlife se convierte en una frase compuesta por dos palabras: Vida, término extremadamente polisémico cuyo significado implica aspectos científicos (biológicos, psicológicos, médicos), sociales, filosóficos, religiosos y culturales. Dentro de un contexto biológico, el concepto de vida es complejo y puede referirse a una lista de características o condiciones necesarias para que exista la vida, por ejemplo 
propiedades que diferencien entre procesos vivos y no vivos como la complejidad, los niveles de organización, peculiaridad química, calidad, unidad y variabilidad, posesión de un programa genético, selección natural, etc. (Kawasaki y El Hani, 2002; El Hani, 2008), o bien a concepciones que van más allá de tales listados y que se basan en las teorías científicas, por ejemplo, la teoría sintética de la evolución, la teoría de la autopoiesis y más recientemente las teorías sobre vida artificial y la cibernética (El Hani, 2008).

La segunda palabra, Silvestre, hace referencia a "aquellos organismos que se crían sin cultivo en selvas o campos" aplicando también el término a lo "Inculto, agreste y rústico" (Diccionario Ilustrado Océano de la Lengua Española, 1997). Dicho diccionario, al igual que el Larousse (Gran diccionario de la lengua española, 2009) no incluyen la frase binominal "vida silvestre". Sin embargo, podemos encontrar su definición en las publicaciones de leyes, acuerdos y resoluciones ambientales de los países latinoamericanos.

Así por ejemplo, la Ley General de Vida Silvestre de México (2000) define a ésta como "los organismos que subsisten sujetos a los procesos de evolución natural y que se desarrollan libremente en su hábitat, incluyendo sus poblaciones menores e individuos que se encuentran bajo el control del hombre, así como los ferales" (articulo 3 XLV, pag. 4).

En el Ecuador, La Ley Forestal y de Conservación de Áreas Naturales y Vida Silvestre (2004) define a la vida silvestre como "la fauna (animales) y flora (plantas) silvestres". A su vez, esta Ley establece que la flora silvestre es "el conjunto de especies vegetales nativas, que crecen espontáneamente" (opus cit. pp. 19), identificando a la flora nativa como los "vegetales propios" del país o de una región. La fauna silvestre está definida allí como "los animales silvestres, sin distinción de clases o categorías zoológicas que viven en forma permanente o temporal en los ecosistemas acuáticos, terrestres y atmosféricos". También considera como vida silvestre "las especies domésticas que, por disposición del Ministerio del Ambiente, deban ser manejadas como silvestres para evitar su extinción, o con fines de control"(opus cit pp. 19)

En Costa Rica, la vida silvestre, según la Ley № 7317 de 1992, estaría conformada por “la fauna continental e insular que vive en condiciones naturales, temporales o permanentemente en el territorio nacional y la flora que vive en condiciones naturales en el país" (Artículo 1, pag. 1).

En Colombia, las primeras menciones relacionadas con la vida silvestre se encuentran en el Código Nacional de Recursos Naturales Renovables y de Protección al Medio Ambiente, Decreto 2811 de 1974. En dicho código no se mencionan las palabras "vida silvestre", aunque sí define la "flora" y "fauna" "silvestres": Artículo 249. "Entiéndase por fauna silvestre el conjunto de animales que no han sido objeto de domesticación, mejoramiento genético o cría y levante regular o que han regresado a su estado salvaje, excluidos los peces y todas las demás especies que tienen su ciclo total de vida dentro del medio acuático" (pp. 64); Articulo 199. "Se denomina flora silvestre el conjunto de especies e individuos vegetales del territorio nacional que no se han plantado o mejorado por el hombre" (pp.55).

Esta visión escindida -flora-fauna- de la vida silvestre ha predominado en las leyes colombianas posteriores, por ejemplo en el Decreto 1608 del 31 de Julio de 1978, por el cual se reglamentan el Código Nacional de los Recursos Naturales Renovables y de Protección al Medio Ambiente y en la Ley 23 de 1973 sobre fauna silvestre; también en el Decreto 1681 del 4 de Agosto de 1978, por el cual se reglamentan la Parte X del Libro II del Decreto-Ley 
2811 de 1974 que trata de los recursos hidro-biológicos y en el Decreto 1974 del 31 de Agosto de 1989, por el cual se reglamenta el artículo 310 del Decreto-Ley 2811 de 1974, sobre Distritos de Manejo Integrado de los Recursos Naturales Renovables; y, finalmente, en la Ley 99 de 1993, por la cual se crea el Ministerio del Medio Ambiente.

Tabla 1. Referentes para el concepto de vida silvestre en Inglaterra, Norteamérica y Latinoamérica

\begin{tabular}{|c|c|c|c|c|}
\hline País & Fecha & $\begin{array}{l}\text { Fuente a través de } \\
\text { la cual se aborda o } \\
\text { difunde el concepto } \\
\text { de vida silvestre }\end{array}$ & \begin{tabular}{|l|} 
Qué especies son \\
incluidas dentro \\
de la concepción \\
de vida silvestre \\
\end{tabular} & $\begin{array}{l}\text { Autor(es) de } \\
\text { referencia }\end{array}$ \\
\hline \multirow[t]{2}{*}{ Inglaterra } & $\begin{array}{l}\text { Siglos XII a } \\
\text { XIX }\end{array}$ & Leyes de Caza & \begin{tabular}{|l} 
Animales de \\
naturaleza salvaje \\
(Ferae naturae)
\end{tabular} & $\begin{array}{l}\text { Blackstone } \\
{[1765-69) .}\end{array}$ \\
\hline & 1831 & $\begin{array}{ll}\text { Abolición } & \text { de } \\
\text { estatutos } & \text { de } \\
\text { calificación } & \\
\end{array}$ & Fauna salvaje & Kirby (1933). \\
\hline \multirow{4}{*}{ Norteamérica } & $\begin{array}{l}\text { Finales del } \\
\text { siglo XIX, } \\
\text { comienzos } \\
\text { del siglo XX }\end{array}$ & \begin{tabular}{lr}
\multicolumn{2}{l}{ Literatura científico- } \\
divulgativa & sobre \\
desaparición & o \\
pérdida de & fauna \\
silvestre &
\end{tabular} & $\begin{array}{l}\text { 1. Fauna salvaje } \\
\text { (wild animals) } \\
\text { 2. Fauna salvaje } \\
\text { de caza (wild } \\
\text { game, mammals } \\
\text { or birds) }\end{array}$ & $\begin{array}{l}\text { Hornaday. } \\
\text { (1913). }\end{array}$ \\
\hline & 1901-1908 & $\begin{array}{l}\text { Promulgación } \\
\text { leyes y creación de } \\
\text { Parques y reservas } \\
\text { para protección y } \\
\text { conservación } \\
\text { fauna silvestre }\end{array}$ & $\begin{array}{l}\text { Fauna salvaje de } \\
\text { caza. }\end{array}$ & $\begin{array}{l}\text { T. Roosevelt } \\
\text { Association, } \\
\text { (2010). }\end{array}$ \\
\hline & $1937-1970$ & $\begin{array}{l}\text { Implementación de } \\
\text { las leyes sobre } \\
\text { Cacería. } \\
\text { Publicaciones } \\
\text { científico- } \\
\text { divulgativas } \\
\text { seriadas }\end{array}$ & $\begin{array}{l}\text { Especies salvajes } \\
\text { de caza mayor y } \\
\text { de caza menor }\end{array}$ & $\begin{array}{l}\text { Revista Wildlife } \\
\text { Management } \\
\text { desde } 1937 \\
\text { hasta ahora }\end{array}$ \\
\hline & $1970-1990$ & $\begin{array}{lr}\text { Libros y artículos } \\
\text { promocionando la } \\
\text { vida al aire libre } \\
\text { (áreas de } & \text { vida } \\
\text { silvestre), } & \\
\text { metodologías para } \\
\text { el estudio de la vida } \\
\text { silvestre } \\
\text { evaluaciones }\end{array}$ & $\begin{array}{l}\text { Wildlife } \\
\text { Nongame species } \\
\end{array}$ & $\begin{array}{l}\text { Crawford } \\
\text { (1976). } \\
\text { Project Wild } \\
\text { (1986). }\end{array}$ \\
\hline
\end{tabular}




\begin{tabular}{|c|c|c|c|c|}
\hline & & $\begin{array}{l}\text { actitudes y valores } \\
\text { sobre las especies } \\
\text { silvestres }\end{array}$ & & \\
\hline & 1990 - actual & $\begin{array}{l}\text { Investigación en } \\
\text { Universidades }\end{array}$ & $\begin{array}{l}\text { Todos los reinos } \\
\text { (plantas, } \\
\text { animales, } \\
\text { protistos, hongos } \\
\text { y procariotes. } \\
\text { Predominio de } \\
\text { publicaciones de } \\
\text { ecología de la } \\
\text { vida silvestre }\end{array}$ & $\begin{array}{l}\text { Spellerberg } \\
\text { (1992). }\end{array}$ \\
\hline & $\begin{array}{l}\text { MEXICO } \\
2000\end{array}$ & $\begin{array}{l}\text { Legislación } \\
\text { ambiental }\end{array}$ & $\begin{array}{l}\text { Organismos libres } \\
\text { en su habitat } y \\
\text { fieras }\end{array}$ & $\begin{array}{l}\text { Ley general de } \\
\text { vida silvestre } \\
(2000)\end{array}$ \\
\hline & $\begin{array}{l}\text { ECUADOR } \\
1981\end{array}$ & $\begin{array}{l}\text { Legislación } \\
\text { ambiental }\end{array}$ & $\begin{array}{l}\text { Fauna y flora } \\
\text { nativas que crecen } \\
\text { espontáneamente. } \\
\text { También especies } \\
\text { domésticas que el } \\
\text { Ministerio asuma } \\
\text { como silvestres }\end{array}$ & $\begin{array}{lr}\text { Ley } & \text { Forestal y } \\
\text { de conservación } \\
\text { der áreas } \\
\text { naturales y vida } \\
\text { silvestre (2004) }\end{array}$ \\
\hline $\begin{array}{l}\text { Centro y } \\
\text { Suramérica }\end{array}$ & $\begin{array}{l}\text { COSTA } \\
\text { RICA } 1992\end{array}$ & $\begin{array}{l}\text { Legislación } \\
\text { ambiental }\end{array}$ & $\begin{array}{l}\text { Fauna y flora } \\
\text { continental } \\
\text { insular que viven } \\
\text { en condiciones } \\
\text { naturales }\end{array}$ & Ley 7317 (1992) \\
\hline & $\begin{array}{l}\text { COLOMBIA } \\
1974\end{array}$ & $\begin{array}{l}\text { Legislación } \\
\text { ambiental }\end{array}$ & $\begin{array}{l}\text { Fauna y flora no } \\
\text { domesticados }\end{array}$ & $\begin{array}{l}\text { Código } \\
\text { Nacional de } \\
\text { Recursos } \\
\text { Naturales } \\
\text { Renovables y de } \\
\text { protección al } \\
\text { medio ambiente } \\
(1974)\end{array}$ \\
\hline
\end{tabular}

La Tabla 1 sintetiza los referentes, esencialmente fauna, que se aplican para definir la vida silvestre en Inglaterra, Norteamérica y algunos países latinoamericanos. Una primera observación es el predominio en Inglaterra y temporalmente -hasta la década de los 70'sen Norteamérica, de la concepción de vida silvestre como animales de caza (game species). Posteriormente, para el caso de Norteamérica, las revistas y libros dedicados a la vida silvestre incluyen artículos sobre animales no declarados como especies de caza (nongame species), luego artículos donde el término "vida silvestre" abarca a las especies de todos los reinos de la naturaleza y finalmente a las especies silvestres concebidas como un sistema de interrelaciones (Figura 1). No obstante, la concepción de vida silvestre como un conjunto de organismos inmersos en relaciones de interdependencia ya era tema de discusión en la 
década de 1930 en las cátedras de Aldo Leopold en la Universidad de Winsconsin (Clay, 1976). Todo ello vislumbra una evolución de la concepción de vida silvestre, no siempre explícita pero sí bastante sugestiva, que se evidencia en la lenta y sucesiva incorporación de otros taxa y en la inclusión progresiva de contenidos ambientales y ecológicos en revistas y libros conocidos clásicamente como literatura dedicada a la vida silvestre (caso Journal of Wildlife Management, Wildlife Monographs, Revista Audubon, etc.).

\section{Figura 1}

Evolución del concepto de vida silvestre en Norteamérica, inferida de los contenidos de revistas y libros con temática central sobre la vida silvestre

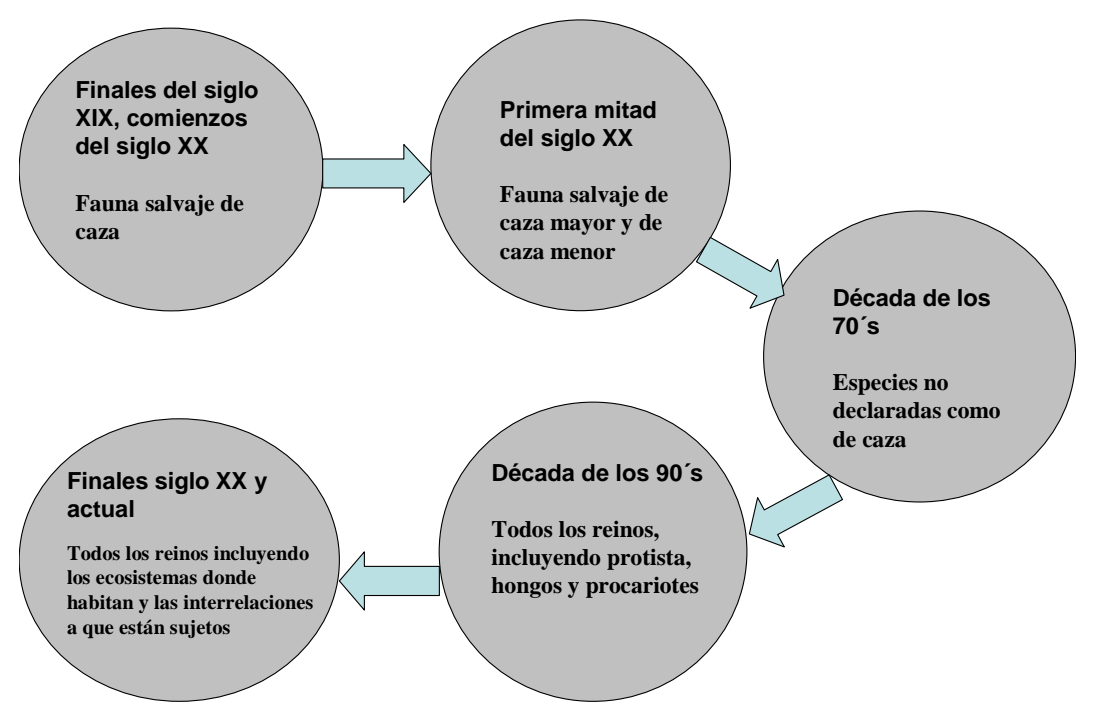

Dicha evolución conceptual no se evidencia en los países latinoamericanos. La palabra vida silvestre hace su aparición en el lenguaje hispano a través de definiciones técnicas reseñadas en las diferentes legislaciones ambientales de Latinoamérica, con tres variaciones importantes: a) incluye a las plantas en la misma categoría de vida silvestre que la fauna y b) no habla de especies de caza, debido quizás a la poca tradición de ese deporte en nuestro continente y c) omite los demás reinos de la naturaleza.

Existe por demás una brecha gigantesca entre el nivel de importancia que se le da a la vida silvestre en Norteamérica en contraste con Suramérica. El concepto de wildlife en Norteamérica tiene una historia de más de cien años, con acepciones que van desde las grandes especies de caza (osos, búfalos), hasta los microorganismos (protistos, hongos y bacterias), pasando por las pequeñas especies de caza (ardillas, pavas, codornices). Las políticas de protección fueron planteadas en un comienzo por cazadores deportivos pudientes, preocupados por la caza indiscriminada, tanto en volumen como en número de especies, por parte de los comerciantes. Con la adquisición de cargos administrativos y políticos en las altas jerarquías, muchos de estos cazadores deportivos (caso T. Rooselvelt, George Bird Grinnell y Gifford Pinchot), establecieron las bases para la legislación de protección y conservación de la vida silvestre (Clay, 1976).

En Suramérica las sociedades u organizaciones privadas de protección a la vida silvestre son más recientes (caso Fundación Vida Silvestre Argentina, una de las más prestigiosas e 
influyentes, fundada en 1977), mientras que los “Clubes de Caza y Pesca han estado dedicados principalmente a la pesca y a las competencias de tiro y no se evidencia que hayan tenido mayor ingerencia en las políticas ambientales (Hurlingham Club, Argentina. 2010; Corporación Club de Caza y Tiro Los Patojos, Colombia. 2010)

Finalmente, cotejando las concepciones sobre vida silvestre de Inglaterra y Norteamérica respecto a los países latinoamericanos, podemos inferir, desde una perspectiva histórica, una tendencia al enriquecimiento de la concepción en un sentido de menor a mayor complejidad, con las siguientes acepciones: 1) Especies de fauna no domesticadas (animales salvajes) 2) Animales de caza deportiva 3) plantas y animales no domesticados 4) plantas y animales que tienen la capacidad de sobrevivir y criarse libremente en la naturaleza 5) organismos que subsisten sujetos a los procesos de evolución natural 6) especies de fauna y flora nativas (de alguna región o país), 7) especies de animales, plantas salvajes, bacterias, hongos y otras, de carácter salvaje, 8) especies de todos los reinos incluyendo los ecosistemas y paisajes de los cuales hacen parte y las interrelaciones con el medio.

\section{LA EDUCACIÓN EN VIDA SILVESTRE}

Es difícil establecer una fecha exacta del inicio de la educación sobre la vida silvestre. A nivel no formal puede mencionarse -para el caso de Norteamérica- la década de 1827 a 1838, período en el que John Audubon publicó sus cuatro volúmenes sobre Las Aves de América (Havell Edition of Audubon Prints, 2010), obra que abrió el camino para la divulgación de las especies silvestres de este continente, con ilustraciones y notas sobre sus habitats (ver Tabla 2).

\section{TABLA 2}

El desarrollo de la educación y de la investigación educativa en torno a la vida silvestre

\begin{tabular}{|c|c|c|c|c|}
\hline Fecha/ País & $\begin{array}{l}\text { Autores, sociedades o } \\
\text { entidades educativas } \\
\text { involucradas en la } \\
\text { educación sobre vida } \\
\text { silvestre }\end{array}$ & $\begin{array}{l}\text { Tipo de } \\
\text { educación }\end{array}$ & Medios de difusión & $\begin{array}{l}\text { Fuente } \\
\text { consultada } \\
\text { /autores }\end{array}$ \\
\hline \multicolumn{5}{|c|}{\begin{tabular}{ll|l} 
INGLATERRA & \\
\end{tabular}} \\
\hline \multirow[t]{3}{*}{1906} & \multirow{3}{*}{$\begin{array}{l}\text { Profesores } \\
\text { independientes }\end{array}$} & \multirow[t]{3}{*}{ Formal } & Libros didácticos: & \\
\hline & & & $\begin{array}{l}\text { La felicidad de vivir con } \\
\text { la naturaleza" }\end{array}$ & $\begin{array}{l}\text { Holden (1906, } \\
\text { facsimil 1979) }\end{array}$ \\
\hline & & & $\begin{array}{l}\text { "Diario ilustrado sobre } \\
\text { la naturaleza" }\end{array}$ & $\begin{array}{l}\begin{array}{l}\text { Holden (1905, } \\
\text { facsimil, 1989) }\end{array} \\
\end{array}$ \\
\hline \multicolumn{5}{|l|}{ USA } \\
\hline 1827 a 1838 & $\begin{array}{l}\text { Investigadores } \\
\text { independientes, Por } \\
\text { ejemplo. John Audubon }\end{array}$ & $\begin{array}{l}\text { No } \\
\text { Formal }\end{array}$ & $\begin{array}{l}\text { Libros y enciclopedias } \\
\text { de lujo (P.ej. Aves de } \\
\text { América) }\end{array}$ & $\begin{array}{l}\text { Havell Edition } \\
\text { of Audubon } \\
\text { Prints (2010) } \\
\end{array}$ \\
\hline $1870-1880$ & $\begin{array}{l}\text { Florecen las Sociedades } \\
\text { y organizaciones } \\
\text { privadas }\end{array}$ & $\begin{array}{l}\text { No } \\
\text { Formal } \\
\end{array}$ & $\begin{array}{ll}\text { Campañas } & y \\
\text { conferencias } & \end{array}$ & \begin{tabular}{|l|} 
Clay \\
Schoenfeld \\
$(1976)$ \\
\end{tabular} \\
\hline $1883-1911$ & Unión Americana de & No & Revista Audubon & Clay \\
\hline
\end{tabular}


Bio-grafia: Escritos sobre la Biologia y su Enseñanza Vol. 4 No. 6 ISSN 2027-1034. Primer semestre de 2011, Bogotá, Colombia, p. p. 51-87

\begin{tabular}{|c|c|c|c|c|}
\hline & $\begin{array}{l}\text { Ornitólogos } \\
\text { Sociedad Nacional } \\
\text { Audubon } \\
\text { George Bird Grinnell }\end{array}$ & Formal & $\begin{array}{l}\text { Semanario Forest and } \\
\text { Stream Magazine }\end{array}$ & $\begin{array}{l}\text { Schoenfeld } \\
(1976)\end{array}$ \\
\hline 1930 & $\begin{array}{l}\text { Universidad de } \\
\text { Winsconsin }\end{array}$ & Formal & $\begin{array}{l}\text { Se inicia la Carrera } \\
\text { "Manejo de la vida } \\
\text { silvestre" }\end{array}$ & \begin{tabular}{|l|} 
Clay \\
Schoenfeld \\
$(1976)$ \\
\end{tabular} \\
\hline 1937 & The Wildlife Society & No formal & \begin{tabular}{|l|} 
Nace el "Journal of \\
Wildlife Management" \\
\end{tabular} & \begin{tabular}{|l} 
The Wildlife \\
Society (2010)
\end{tabular} \\
\hline 1958 & The Wildlife Society & No formal & $\begin{array}{l}\text { Nace "Wildlife } \\
\text { Monographs" }\end{array}$ & \begin{tabular}{|l} 
The Wildlife \\
Society (2010)
\end{tabular} \\
\hline \multirow[t]{3}{*}{$1949-2005$} & \multirow{3}{*}{$\begin{array}{l}\text { Autores de literatura } \\
\text { sobre vida silvestre más } \\
\text { leídos en Norteamérica } \\
\text { y en el mundo: Aldo } \\
\text { Leopold (1949), Rachel } \\
\text { Carlson (1962), Scott } \\
\text { Weidensaul (2005) }\end{array}$} & \multirow{3}{*}{\begin{tabular}{|l|} 
No formal \\
\end{tabular}} & $\begin{array}{l}\text { Almanaque del condado } \\
\text { de arena de Aldo Leopold }\end{array}$ & $\begin{array}{l}\text { The Reviewer's } \\
\text { List (2010) }\end{array}$ \\
\hline & & & $\begin{array}{l}\text { Primavera silenciosa de } \\
\text { Rachel Carson }\end{array}$ & $\begin{array}{l}\text { The Reviewer's } \\
\text { List (2010) } \\
\end{array}$ \\
\hline & & & $\begin{array}{l}\text { Retorno a la América } \\
\text { Salvaje: un año de } \\
\text { búsqueda para el alma } \\
\text { natural } \\
\text { continente", de Scott } \\
\text { Weidensaul }\end{array}$ & $\begin{array}{l}\text { Weidensaul } \\
\text { Scott (2005) }\end{array}$ \\
\hline
\end{tabular}

TABLA 2 (CONTINUACION)

El desarrollo de la educación y de la investigación educativa en torno a la vida silvestre

\begin{tabular}{|c|c|c|c|c|}
\hline Fecha & $\begin{array}{l}\text { Autores, sociedades o } \\
\text { entidades educativas } \\
\text { involucradas en la } \\
\text { educación sobre vida } \\
\text { silvestre }\end{array}$ & $\begin{array}{l}\text { Tipo de } \\
\text { educación }\end{array}$ & Medios de difusión & $\begin{array}{l}\text { Fuente } \\
\text { consultada } \\
\text { /autores }\end{array}$ \\
\hline \multirow[t]{2}{*}{$\begin{array}{l}1970 \\
\text { presente }\end{array}$} & $\begin{array}{l}24 \text { Departamentos } \\
\text { Estatales de Educación } \\
\text { de los Estados Unidos. }\end{array}$ & \begin{tabular}{|lll}
$\begin{array}{l}\text { Formal } \\
\text { formal }\end{array}$ & \\
\end{tabular} & \begin{tabular}{|lr} 
Project Wild & : \\
Programa & \\
interdisciplinario & de \\
educación sobre la vida \\
silvestre & para \\
estudiantes & de \\
secundaria & \\
\end{tabular} & $\begin{array}{l}\text { Project Wild } \\
(1986)\end{array}$ \\
\hline & $\begin{array}{l}\text { Universidades } \\
\text { públicas y privadas. } \\
\text { También autores } \\
\text { independientes }\end{array}$ & $\begin{array}{l}\text { Formal y No } \\
\text { formal } \\
\text { Libros sobre } \\
\text { técnicas de } \\
\text { observación y } \\
\text { materiales para }\end{array}$ & $\begin{array}{l}\text { Guía práctica ilustrada } \\
\text { para los amantes de la } \\
\text { naturaleza. } \\
\text { Multidisciplinary } \\
\text { Wildlife Teaching }\end{array}$ & $\begin{array}{l}\text { Michael } \\
\text { Chinery (1979) } \\
\text { William } \\
\text { Hernbrode Ed. }\end{array}$ \\
\hline
\end{tabular}




\begin{tabular}{|c|c|c|c|}
\hline & $\begin{array}{l}\text { estudio de la } \\
\text { vida silvestre }\end{array}$ & $\begin{array}{l}\text { Activities } \\
\text { Free and inexpensive } \\
\text { materials for teaching } \\
\text { conservation: wildlife } \\
\text { and fish section. }\end{array}$ & $\begin{array}{l}(1978) \\
\text { Genevieve } \\
\text { Cousins and } \\
\text { Ronnie Mae } \\
\text { Smith (1968) }\end{array}$ \\
\hline $\begin{array}{l}\text { Universidades } \\
\text { públicas y privadas. } \\
\text { También autores } \\
\text { independientes }\end{array}$ & \begin{tabular}{|l} 
Formal \\
Publicaciones \\
en revistas \\
científicas : \\
Investigaciones \\
sobre actitudes \\
y valores hacia \\
la vida \\
silvestre
\end{tabular} & $\begin{array}{l}\text { Youth and Wildlife:The } \\
\text { Beliefs and Behaviors } \\
\text { of Fifth and Sixth } \\
\text { Grade Students } \\
\text { Regarding Non- } \\
\text { Domestic Animals } \\
\text { The Influence of } \\
\text { Knowledge on Young } \\
\text { people's Perceptions } \\
\text { About Wildlife .. Final } \\
\text { Project Reports to the } \\
\text { National Wildlife } \\
\text { federation } \\
\text { Human Conditioning } \\
\text { to Wildlife: Steps } \\
\text { Toward Theory and } \\
\text { Research } \\
\begin{array}{l}\text { Toward Animals in } \\
\text { American Society. } \\
\text { Phase III. }\end{array} \\
\text { Knowledge, Affection } \\
\text { Basic Attitudes }\end{array}$ & 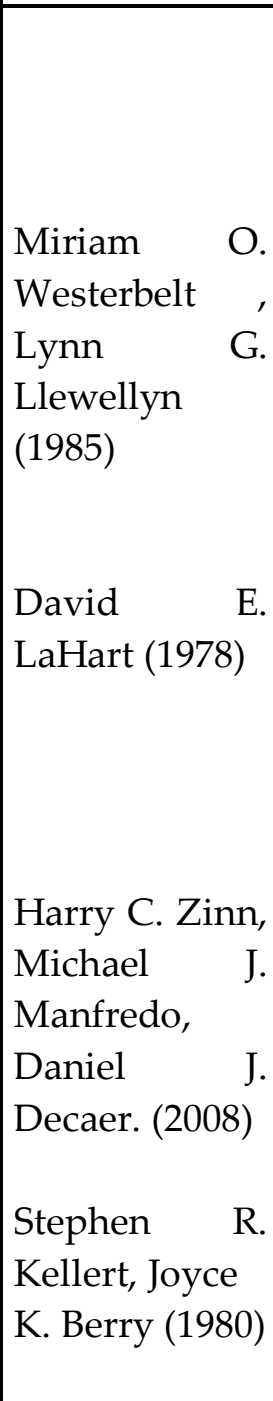 \\
\hline \begin{tabular}{|l}
\multicolumn{2}{|l}{ Universidades } \\
públicas y privadas. \\
También autores \\
independientes
\end{tabular} & \begin{tabular}{|l|} 
Formal \\
Publicaciones \\
sobre \\
actividades \\
para \\
enseñanza - \\
aprendizaje \\
sobre la vida \\
Silvestre.
\end{tabular} & $\begin{array}{l}\text { Activities for studying } \\
\text { wildlife, grade level 4-6 } \\
\text { Environmental } \\
\text { education and wildlife } \\
\text { conservation }\end{array}$ & $\begin{array}{l}\text { Environmental } \\
\text { Education } \\
\text { Series, Bulletin } \\
\text { no.247-b. } \\
\text { Montgomery } \\
\text { County Public } \\
\text { Schools, } \\
\text { Rockville, Md. } \\
(1970)\end{array}$ \\
\hline
\end{tabular}




\begin{tabular}{|c|c|c|c|}
\hline & & $\begin{array}{l}\text { Outdoor } \quad \begin{array}{r}\text { Recreotion } \\
\text { and } \\
\text { Management } \\
\text { Resources. }\end{array} \\
\\
\begin{array}{l}\text { Multidlife } \\
\text { wildlife } \quad \text { teaching } \\
\text { activities }\end{array}\end{array}$ & $\begin{array}{l}\text { Clay } \\
\text { Schoenfeld } \\
(1976) \\
\\
\text { Alaska State } \\
\text { Department of } \\
\text { Education, } \\
\text { Juneau. Div. of } \\
\text { Adult and } \\
\text { Vocational } \\
\text { Education } \\
\text { (1989) } \\
\text { William R. } \\
\text { Hernbrode } \\
\text { (Ed). (1978) }\end{array}$ \\
\hline $\begin{array}{l}\text { Universidades } \\
\text { públicas y privadas. } \\
\text { También autores } \\
\text { independientes }\end{array}$ & $\begin{array}{l}\text { Formal } \\
\text { Publicaciones } \\
\text { sobre vida } \\
\text { Silvestre en } \\
\text { relación con el } \\
\text { habitat en el } \\
\text { ámbito de las } \\
\text { universidades }\end{array}$ & $\begin{array}{l}\text { School Ground Habitat } \\
\text { for People and Wildlife } \\
\text { Wildlife and the School } \\
\text { Environment. } \\
\text { Nongame wildlife the } \\
\text { role of the university }\end{array}$ & \begin{tabular}{|l}
$\begin{array}{l}\text { Glenn R. } \\
\text { Dudderar and } \\
\text { others. (1996) }\end{array}$ \\
Winchester \\
Trust (1992) \\
\\
John A. \\
$\begin{array}{l}\text { Crawford } \\
(1976)\end{array}$ \\
\end{tabular} \\
\hline $\begin{array}{lr}\text { Florecimiento } & \text { de } \\
\text { nuevas carreras } & \text { y } \\
\text { profesiones } & \\
\text { universitarias } & \\
\text { relacionadas con la } \\
\text { vida silvestre }\end{array}$ & Formal & 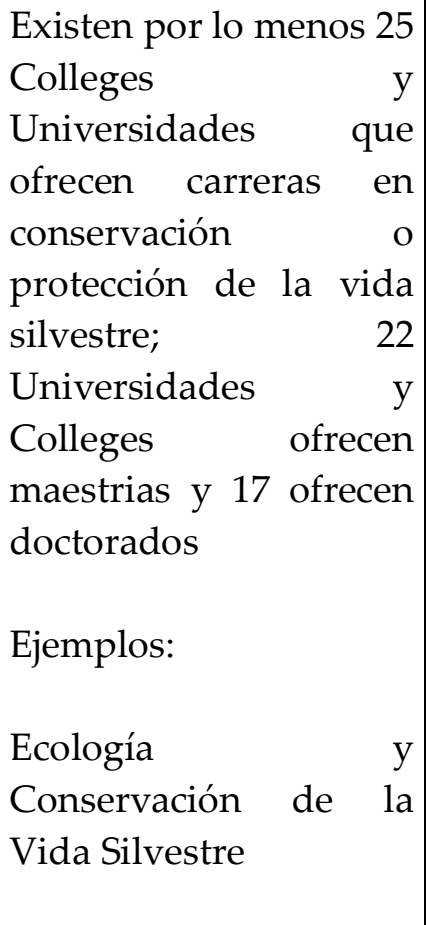 & \begin{tabular}{|l} 
\\
Universidad \\
de la Florida \\
Universidad \\
de Minnesota \\
Universidad
\end{tabular} \\
\hline
\end{tabular}




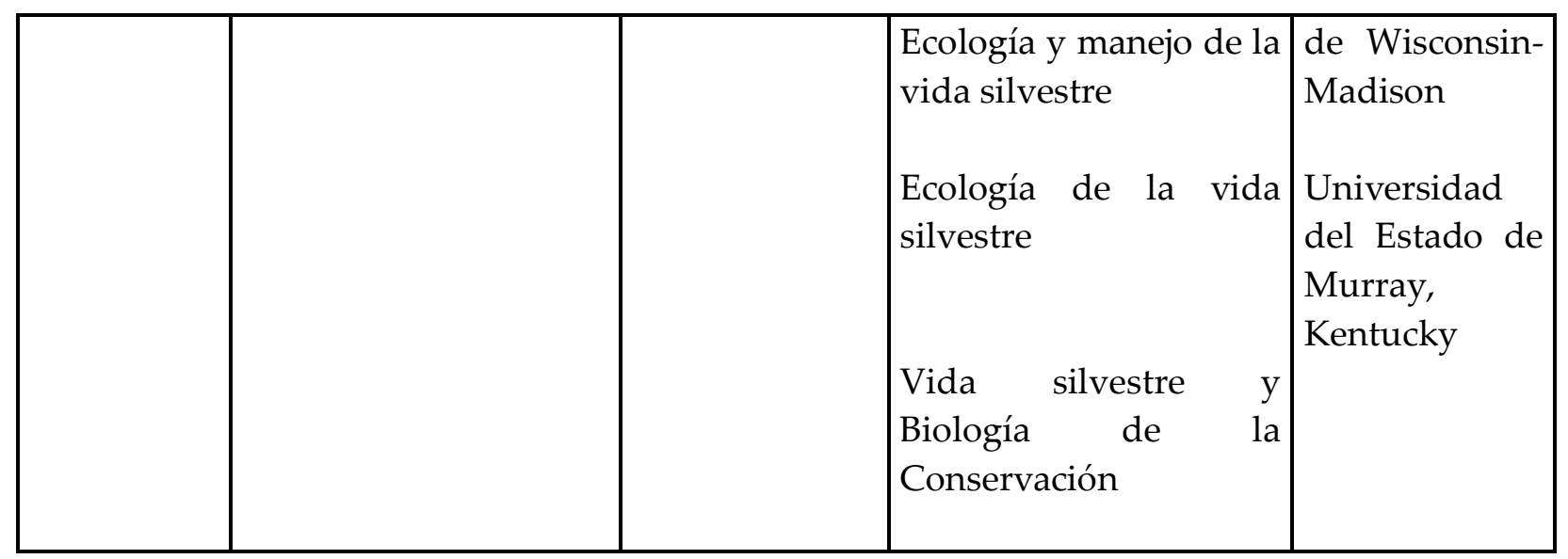

TABLA 2 (CONTINUACION)

El desarrollo de la educación y de la investigación educativa en torno a la vida silvestre

\begin{tabular}{|c|c|c|c|c|}
\hline Fecha & $\begin{array}{l}\text { Autores, sociedades o } \\
\text { entidades educativas } \\
\text { involucradas en la } \\
\text { educación sobre vida } \\
\text { silvestre }\end{array}$ & $\begin{array}{l}\text { Tipo de } \\
\text { educación }\end{array}$ & $\begin{array}{l}\text { Medios de } \\
\text { difusión }\end{array}$ & $\begin{array}{l}\text { Fuente } \\
\text { consultada } \\
\text { /autores }\end{array}$ \\
\hline \multicolumn{5}{|c|}{ COLOMBIA } \\
\hline 1974 & $\begin{array}{l}\text { La vida silvestre está } \\
\text { referenciada por el } \\
\text { Instituto Nacional de } \\
\text { los Recursos Naturales } \\
\text { INDERENA }\end{array}$ & $\begin{array}{l}\text { No se } \\
\text { evidencia } 1\end{array}$ & $\begin{array}{l}\text { Código Nacional } \\
\text { de los Recursos } \\
\text { Naturales }\end{array}$ & $\begin{array}{l}\text { Diario Oficial No } \\
34.243 \text { de } 1975\end{array}$ \\
\hline $\begin{array}{l}1974 \text { - } \\
\text { presente }\end{array}$ & $\begin{array}{l}\text { Autores de literatura } \\
\text { sobre vida silvestre }\end{array}$ & 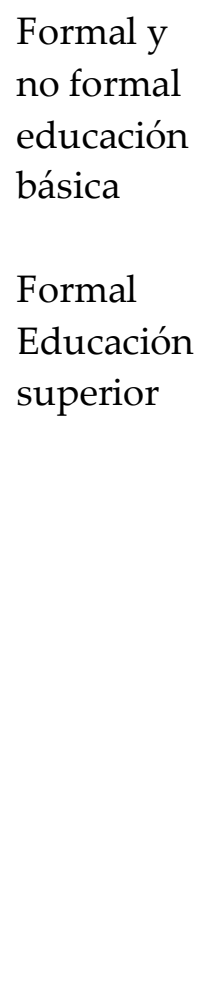 & $\begin{array}{l}\text { No se conocen } \\
\text { autores ni libros } \\
\text { de texto con } \\
\text { temática sobre } \\
\text { vida silvestre } \\
\text { No se conocen } \\
\text { publicaciones } \\
\text { seriadas (revistas } \\
\text { indexadas o de } \\
\text { divulgación) ni } \\
\text { libros de texto } \\
\text { con títulos } \\
\text { referidos a la } \\
\text { vida silvestre. }\end{array}$ & $\begin{array}{l}\text { Viajeros } 4 \text { y } 5 \\
(2008) \\
\\
\text { Bases de } \\
\text { datos: Eric, } \\
\text { Biblioteca } \\
\text { Miguel de } \\
\text { Cervantes, } \\
\text { Jstor, Google, } \\
\text { Biblioteca } \\
\text { Universidad } \\
\text { Nacional y } \\
\text { otras. } \\
\text { Textos } \\
\text { universitarios de } \\
\text { ecología: Curtis }\end{array}$ \\
\hline
\end{tabular}




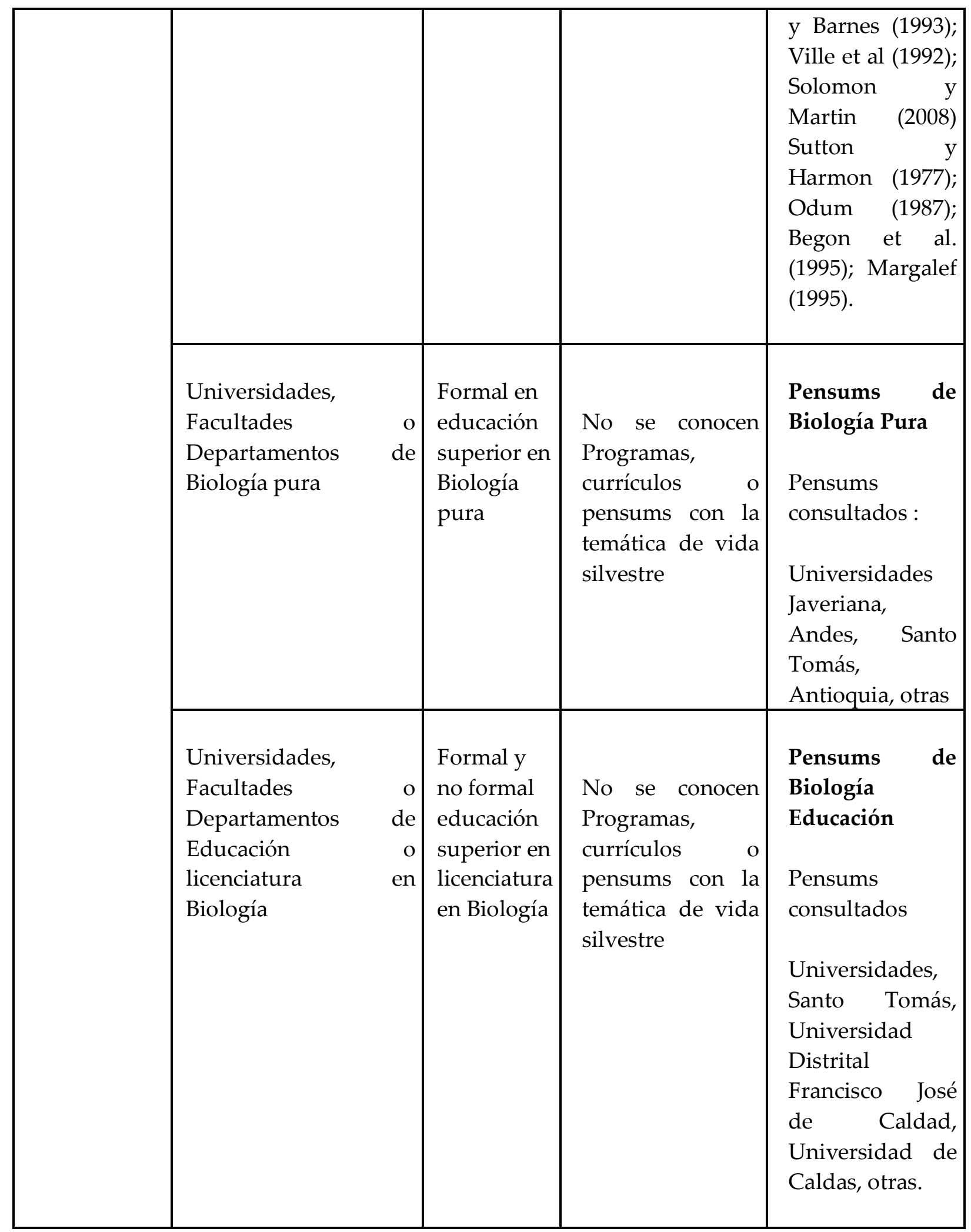

Hacia 1870 muchos amantes del aire libre y observadores de aves de los Estados Unidos, conscientes de los problemas relacionados con la pérdida de los bosques y la cacería comercial, comenzaron a formar organizaciones de voluntarios e iniciar campañas educativas en pro de la vida silvestre (Clay, 1976). 
En 1883 se conforma la Unión Americana de Ornitólogos, de carácter divulgativo y de defensa de la vida silvestre, quienes dos décadas más tarde se unen a la Sociedad Nacional Audubon para conformar lo que ellos llamaron "la fuente de la cual emergió la mayor parte del movimiento moderno de conservación" (Clay, 1976).

En 1887 nace la revista Audubon, una de las publicaciones más antiguas de este tipo en el mundo, cuyo objetivo era "discutir los problemas generales de la vida animal en relación con la agricultura y el bienestar humano" (Berle Meter, 1987, pp. 4). En esta misma tónica, George Bird Grinnell editó entre 1876 y 1911 el semanario Forest and Stream Magazine y una serie de cuentos de tipo naturalista protagonizadas por un héroe ficticio llamado "Jack" (Mitchell, 1987) cuyas aventuras, complementadas y enriquecidas por dicho autor en exposiciones multitudinarias dictadas en Clubes, Sociedades, Museos e Institutos, fueron educando al público y a los políticos entre los que se contaba T. Roosevelt. La amistad de Grinnell con Roosevelt dio muy buenos frutos. Como presidente, Roosevelt inició toda una serie de reformas en la política ambiental, plantando "las semillas de muchos de los conceptos progresistas de protección del medio ambiente" (Mitchell, 1987, pp 92). A lo largo de su administración Roosevelt creó 150 reservas forestales, 51 refugios de vida silvestre y 5 parques nacionales (T. Roosevelt Association, 2010). Otro de los amigos de Roosevelt era Gifford Pinchot, gran pionero de la educación sobre la vida silvestre y jefe del Servicio Forestal de la Infantería de los Estados Unidos. Se le considera el padre de la nueva ética conservacionista, filosofía que cristalizó con la memorable frase "el mayor bien para el mayor número, por el mayor tiempo" (Van Dyke, 2003 pp. 10).

Para el caso de Inglaterra durante el intervalo 1900-1930 e inclusive hasta la década de los 70 's, es difícil encontrar información sobre libros y revistas relacionados con la vida silvestre utilizando los motores de búsqueda habituales (Eric, Jstor, Biblioteca Virtual Cervantes, Google.com, etc.). Conocemos dos magníficos textos, bellamente ilustrados de la profesora Edith Holden, escritos en 1906 en Inglaterra. Dichos textos, antes de constituir un material escrito para su edición fue ante todo un material didáctico para las estudiantes de Solihull School, Inglaterra, en donde Holden dictaba clases de arte (Morning Heart, 2010). Redescubiertos a mediados de los setentas, fueron editados como facsímiles en inglés y español con los nombres "La felicidad de vivir con la naturaleza" (Holden, 1906, facsimil 1980) y "Diario ilustrado sobre la naturaleza" (Holden, 1905, facsimil, 1989), alcanzando un éxito rotundo de más de seis millones de copias vendidas hasta el 2000 (Morning Heart, 2010).

En 1937 se inicia en los Estados Unidos la edición del Journal of Wildlife Management (JWM), una de las revistas líderes en ciencia, manejo y conservación de la vida silvestre en el mundo. En 1958 la revista se amplía con la edición de Wildlife Monographs, suplemento dedicado a la revisión y divulgación científica de especies silvestres y sus problemas específicos (The Wildlife Society, 2010).

Puede decirse que la educación sobre la vida silvestre en sus inicios estuvo confinada, en los países del norte, a las ediciones privadas, las más veces lujosas, y a conferencias de un puñado de amantes de la naturaleza quienes, en su mayor parte financiaron sus obras con recursos propios. Posteriormente, y sin perder la mirada conservacionista, se han seguido editando estupendas obras, de carácter literario, filosófico y naturalista, pero esencialmente críticas que, sin lugar a dudas, han influido y cambiado la mentalidad de los norteamericanos (y de muchos lectores en todo el mundo). Resaltamos "Almanaque del 
condado de arena" de Aldo Leopold, publicado en 1949; "Primavera silenciosa" de Rachel Carlson, el más influyente de todos, publicado en 1962, en que se critica el uso masivo de pesticidas químicos (The Reviewer's List: Ten Most Infuential Environmental Books of the 20th Century. 2010) y "Retorno a la América Salvaje: un año de búsqueda para el alma natural del continente", de Scott Weidensaul, finalista del premio Pulitzer por su obra naturalista (Weidensaul, 2005).

A partir de 1930 se institucionaliza en los Estados Unidos la educación sobre la vida silvestre con el surgimiento de la profesión emergente "Manejo de la vida silvestre" en la universidad de Winsconsin, con fuerte influencia del pensamiento ecológicoconservacionista de Aldo Leopold. Los maestros, conscientes ya en esa época de que los cambios y procesos de la vida silvestre era producto del hábitat, comenzaron a enseñar aspectos básicos sobre interacción, interrelaciones e interdependencia (Clay, 1976).

Con el tiempo, se incrementaron las publicaciones científicas y divulgativas, pasando de las ediciones de lujo a ediciones económicas para todas las clases sociales y, hacia los 70's, la vida silvestre se consolida como carrera académica en casi todas las universidades de Norteamérica. En la actualidad puede decirse que para este país, la mayoría de los Estados tiene por lo menos una universidad con pregrado o postgrado relacionado con la vida silvestre (Uniguru: The study abroad site for indian students, 2010). Según este portal, 25 Universidades y Colleges en Estados Unidos ofrecen carreras en conservación o protección de la vida silvestre; 22 Universidades y Colleges ofrecen maestrías y 17 ofrecen doctorados. Ejemplo de ello son el Departamento de Ecología de la Vida Silvestre, de la Universidad de Maine (http://www.wle.umaine.edu/), el Departamento de Ecología y Conservación de Vida Silvestre, de la Universidad de la Florida (www.wec.ufl.edu/) y el Departamento de Bosques y Ecología de la Vida Silvestre de la Universidad de Wisconsin (http://www.cals.wisc.edu/students/majors/wildlife_Ecology.php), fundado en 1933 por Aldo Leopold quien igualmente funda en 1939 el Departamento de Manejo de la Vida Silvestre, primer Departamento académico del mundo en esta área. Es importante observar los títulos de las carreras, para cerciorarnos de la importancia que en la actualidad se da a todos los aspectos ecológicos de la vida silvestre.

\section{LA INVESTIGACIÓN EN EDUCACION SOBRE LA VIDA SILVESTRE}

Como se mencionó en el capitulo anterior, los primeros estudios sobre vida silvestre son de corte naturalista con una evolución hacia la incorporación del medio ambiente y la ecología. A partir de los 70's, viene un periodo de proliferación de investigaciones de corte didáctico, relacionadas con la planificación de actividades al aire libre, manejo de recursos y evaluación de actitudes y valores de los estudiantes sobre la vida silvestre (Alaska State Department of Education, 1989; Westervelt y Llewellyn, 1985; Kellert S. R. 1986.). Algunos de estos documentos, realizados sobre muestras bastante considerables mostraban, por ejemplo, un rechazo generalizado a la caza deportiva (Westervelt y Llewellyn, 1985); muchos otros mostraban la importancia de incorporar en las clases el habitat y las interrelaciones de la vida silvestre (Hernbrode , 1978; Tunstall et al, 1998; Leedy, 1978). Gran parte de los documentos publicados después de 1980 tuvieron como modelo a uno de los más ambiciosos programas interdisciplinarios de educación sobre la vida silvestre para profesores de educación básica secundaria, editado con el título Project Wild (1986, con ediciones en 1983 y 1985), respaldado por 24 Departamentos estatales de educación. En este 
documento, la concepción de vida silvestre incluye una gama amplia de organismos: "For instructional purposes in Project WILD, wildlife is defined as any non-domesticated animal. Wildlife may be small organisms only visible to people if seen through a microscope, or as large as a great blue whale. Wildlife includes, but is not limited to, insects, spiders, birds, reptiles, fish, amphibians, and mammals, if non-domesticated" (Project Wild, 1986 pp. VII, Preface).

En este período se popularizaron igualmente los libros guía sobre técnicas de observación de fauna y metodologías para encontrar indicios de presencia de vida silvestre (Chinery, 1979, Smith, 1982; Johnson, 1997, Elbroch, 2003,). En ellos se enfatiza el desarrollo de habilidades de observación de fauna silvestre bien sea de manera directa o bien mediante el reconocimiento y análisis de huellas y otros indicios (heces, pelos, egagrópilas, etc.). Estas guías están dirigidas principalmente a profesores y estudiantes que tengan actividades al aire libre y muchas de las técnicas tienen aplicabilidad en el trópico (Smith, 1982).

Con el florecimiento y diversificación de nuevas carreras y profesiones relacionadas con la vida silvestre (por ejemplo, Ecología y Conservación de la Vida Silvestre -Universidad de la Florida; Ecología y manejo de la vida silvestre -Universidad de Minnesota; Ecología de la vida silvestre - Universidad de Wisconsin-Madison; Ecología de la vida silvestre Universidad del Estado de Washington, Vida silvestre y Biología de la Conservación Universidad del Estado de Murray, Kentucky, etc., etc. Ver tabla 2) se reforzaron las investigaciones evaluativas, principalmente la aplicación de encuestas sobre necesidades logísticas y de investigación de los maestros de las nacientes carreras (Eastmond, 1975) y la realización de recopilaciones sobre la literatura publicada, por ejemplo, el acceso a material bibliográfico y materiales de enseñanza (Genevieve y Smith, 1968).

En Latinoamérica, la proporción de publicaciones sobre vida silvestre, bien sean de editoriales privadas o estatales, respecto a las publicaciones norteamericanas, es muy pobre, casi nula (Tabla 2). Quizás la más importante sea Vida Silvestre, fundada en 1982 por la Fundación Vida Silvestre Argentina. Para Colombia, uno de los países más ricos del mundo en vida silvestre, no se conocen publicaciones seriadas (revistas indexadas o de divulgación) ni libros de texto con títulos referidos a la vida silvestre, con excepción quizás (aunque sigue ausente el término vida silvestre), de los libros rojos (Serie Libros Rojos de Especies Amenazadas de Colombia, 2010) sobre especies amenazadas -todas ellas silvestres- publicados por el Instituto Von Humboldt. Son 8 libros que abarcan casi todos los grupos de fauna y 2 dedicados a las plantas superiores y a los briofitos. Es diciente que en nuestro país solo se haya divulgado por la Web un homónimo de la revista argentina Vida Silvestre, en cuyo editorial del primer número, (Vida Silvestre Colombia, 2006), se manifiesta la intención de publicar solo artículos dedicados a los "animales domésticos". Igualmente, los libros de texto para educación básica primaria, tomando como ejemplo los libros de ciencias de la editorial Norma (Calderón et al.2008a, Calderón et al.2008b, Camero y , Sánchez, 2008), aunque profusamente ilustrados con especies de vida silvestre, no abordan la discusión en torno a ella ni siquiera en los capítulos de Ecología y Biología de la Conservación. A nivel universitario, con excepción de la literatura especializada de origen norteamericano y europeo, no es posible encontrar referencias a la vida silvestre en textos de biología (p. ej. Curtis y Barnes, 1993; Ville et al, 1992; Solomon y Martin, 2008) ni de ecología (p. ej. Sutton y Harmon, 1977; Odum, 1987; Begon et al, 1995, Margalef, 1995). Excepcionalmente es posible encontrar algunas referencias en cartillas divulgativas de medio ambiente, por ejemplo, Jardín Botánico J. C. Mutis E Universidad Nacional de Colombia 
(2010), en donde se resalta la importancia de la flora silvestre en medicina, alimentación, construcción y decoración. Ello pone de manifiesto que no se aborda de manera explícita la vida silvestre como contenido de enseñanza de las ciencias en textos de uso frecuente tanto en educación básica como superior. Sin embargo, paradójicamente, la mayor parte de textos, tablas, gráficas y dibujos en temáticas tales como niveles tróficos, diversidad de comunidades, competencia, etc. suelen señalar ejemplos de vida silvestre sin identificarla como tal.

Cabe preguntarse, ¿en donde se encuentran referencias a la vida silvestre en Colombia? Al contrario de Norteamérica, en donde la legislación, la educación, las artes, la publicidad, la ciencia y la cultura están embebidas de la concepción de vida silvestre, en nuestro país (el más rico en aves y anfibios silvestres del mundo, el $3^{\circ}$ en reptiles, el $4^{\circ}$ en mamíferos y el $2^{\circ}$ en plantas vasculares silvestres (Ambiental.net. 2010.) solo se ha tenido en cuenta, de manera sesgada, en la primera legislación sobre recursos naturales, la cual no ha sufrido cambios en más de 30 años a partir de su creación (Decreto 2811 de 1974). Las Carreras más afines a la concepción de vida silvestre, a saber Biología pura (ver p. ej. los pensum de las Universidades Javeriana ${ }^{1}$; Andes ${ }^{2}$; y $\mathrm{Nacional}^{3}$, entre otras) y Biología licenciatura (ver pensum de las Universidades de Caldas*1, Santo Tomás*2 y Distrita Francisco José de Caldas1*3), es decir, la biología en sus miradas desde la práctica de campo y laboratorio y desde la didáctica, nunca han tenido, desde su nacimiento (año 1965 con la Carrera de Biología de la Universidad Nacional de Colombia - Correa de Restrepo, 2005), siquiera una cátedra sobre vida silvestre, con excepción del curso "Percepción y apreciación de la vida silvestre" dictada hace 14 años por el autor de este artículo, en la Universidad Nacional de Colombia.

Esta situación resulta insólita, teniendo en cuenta las inquietudes del Ministerio de Educación Nacional cuando a comienzos de los 90's inquiría sobre las razones del escaso impacto de la educación ambiental en Colombia (Torres, 1998). Algunas de las conclusiones del estudio de esta autora hacen referencia precisamente a la carencia de investigación en educación ambiental, a los problemas de conceptualización y a la falta de claridad sobre los procesos pedagógicos y didácticos. Hoy, doce años después de dicho estudio, muchos de los problemas enunciados siguen vigentes -caso de la claridad en los conceptos del medio ambiente, - situación que pone de relieve la poca importancia que el Estado concede a la problemática ambiental. Pensamos, sin embargo, que, además de las razones enunciadas en el mencionado estudio (Torres, 1998), existirían otras razones de fondo para este descuido. En el caso concreto de la vida silvestre, su desconocimiento en los medios académicos podría explicarse de manera similar a la dificultad que tuvo la educación ambiental para incorporarse a la academia: juntas, educación ambiental y educación en vida silvestre, nacieron y crecieron fuera del contexto escolar a partir de iniciativas de organismos no gubernamentales, clubes y sociedades privadas; pero a diferencia de los Estados Unidos, donde muchos de los defensores de la vida silvestre también incursionaron en la docencia y en la política, en Latinoamérica, ante la falta de estos promotores, ha habido consuetudinariamente una fuerte resistencia de la escuela para incorporar temáticas y perspectivas, difíciles de integrar en los marcos académicos (García Díaz, 1994). Así por ejemplo, la educación sobre la vida silvestre, difundida a comienzos del siglo XIX en Norteamérica mediante textos de lujo y conferencias de tipo local, y posteriormente, después de 1930, mediante difusión de revistas científicas especializadas y creación de 
Carreras universitarias, no alcanzó un reconocimiento en el ámbito académico colombiano cuyos currículos, para el caso de la primera

${ }^{1}$ http://puj-

portal.javeriana.edu.co/portal/page/portal/Facultad\%20de\%20Ciencias/1_pdfs_plan_pregra dos/plan_estudio_biologia.pdf

${ }^{2} \mathrm{http}: / /$ cienciasbiologicas.uniandes.edu.co/biologia.htm

${ }^{3}$ http://www.biologia.unal.edu.co/

${ }^{*} 1 \mathrm{http}$ ://www.ucaldas.edu.co/index.php?option=com_content\&view=category\&id=71\&Item id $=660$

${ }^{*}{ }^{2} \mathrm{http}$ ://www.educaedu-colombia.com/licenciatura-en-biologia-con-enfasis-en-educacionambiental-carreras-universitarias-24439.html

*3http://www.udistrital.edu.co/academia/pregrado/licbiologia/plan-de-estudios/

carrera de Biología, año 1965, estuvieron fuertemente influidos por la tradición taxonómica (principalmente botánica, y en menor escala zoológica) proveniente de la Expedición Botánica (Restrepo, 1986), dando como resultado un pensum con unidades temáticas cargadas hacia estas áreas: Biosistemática, Herbario, Ornitología, Mastozoología, Herpetología y Entomología (Correa de Restrepo, 2005); el resto de asignaturas, para el caso concreto de la Carrera de Biología de la Universidad Nacional, con excepción de la ecología, fueron en su mayor parte dictadas por bacteriólogos ante la ausencia de biólogos profesionales, estando ausente en todos los casos la perspectiva de la vida silvestre.

\section{IMPORTANCIA DE LA VIDA SILVESTRE}

La importancia de la vida silvestre se ha planteado generalmente bajo dos ópticas diferentes: $1 \mathrm{su}$ importancia directa (consumo) e indirecta (bienes ambientales) para la supervivencia del hombre y $\mathbf{2}$, su importancia per se, es decir, la perspectiva que considera sus derechos éticos a la supervivencia.

\section{1 importancia de la vida silvestre para la supervivencia humana}

\subsubsection{Aspectos de alimentación y consumo}

Es indudable que hay una fuerte conexión entre nuestra calidad de vida y la vida silvestre. Desde un punto de vista de explotación y consumo, la vida silvestre es considerada un recurso natural renovable de importancia similar a la del agua, el aire y el suelo (Maldonado, 2004). Se considera que aproximadamente un millón y medio de especies silvestres tienen un valor utilitario para el hombre a través del mercado (Díaz-Martín, 1993). Este punto de vista utilitario ya era fuertemente criticado por Aldo Leopold, uno de los más grandes naturalistas de Norteamérica, fundador de las cátedras de Ecología y Manejo de la vida silvestre, cuando a comienzos de la década de los 30 y basándose en sus estudios y experiencia obtenida en el Servicio Forestal donde trabajó durante muchos años, manifestó su inconformidad con la "ética" de la conservación de la vida silvestre concebida como recurso, no solo por ser una ética inadecuada sino también falsa (Van Dyke, 2003). La "tierra" (land), según Leopold, no era como la representaba la ética naturalista de ese tiempo "una colección de diversas mercancías separadas que podían cosecharse independientemente 
sino todo lo contrario, un sistema de procesos interdependientes" (Leopold, 1966 en Van Dyke, 2003, pp. 4), y el resultado de esos procesos, cuando funcionaban apropiadamente, era la producción sostenida de los productos primarios, como el suelo, el agua, la madera, la flora, la fauna y el forraje para los animales silvestres y domésticos. Aunque la visión de Leopold se sustentaba en las concepciones científicas y en su experiencia en el manejo de vida silvestre, se dio cuenta que debería haber también una transformación ética tanto en los directores de recursos como en el público. Leopold estaba convencido que no había una sola manera para el manejo de los recursos, sino "una mejor manera". Tal manejo reconocía que "la tierra" tenía un valor intrínseco per se e incorporaba el sentido ético que reconocía dicho valor y propendía por la salud de la tierra y la productividad continua. Sin estos valores, "el consumismo humano frustraría la mejor información científica y el más ilustre manejo" (Leopold, en Van Dyke, 2003, pp. 4).

Desde otra perspectiva, los valores "utilitaristas" se pueden dividir en dos grandes grupos: los valores directos o bienes privados y los indirectos o bienes públicos (Maldonado, 2004). Los valores directos se asignan a los productos silvestres que son cosechados y usados por el hombre y pueden dividirse a su vez en valores de uso de tipo consuntivo y de tipo productivo. Los primeros se aplican a los bienes como los bosques, que son consumidos localmente, pero que no tienen un papel en la economía nacional e internacional; los segundos, se asignan a las poblaciones que son cosechadas del medio natural y tiene un mercado nacional o internacional.

Los valores indirectos, considerados como los más complejos e importantes, proveen beneficios económicos sin intervención directa sobre las poblaciones silvestres. Dentro de ellos encontramos valores de tipo no consuntivo, dados por los servicios ambientales que prestan los ecosistemas, como la productividad ecosistémica (capacidad de fijar energía solar), regulación del clima, retención de agua y nutrientes, ecoturismo y recreación. Márquez (1996, pp. 2) relaciona estos valores con los llamados ecosistemas estratégicos, es decir, "áreas específicas del territorio donde se concentran funciones naturales, de las que dependen, de manera especial y significativa, bienes y servicios ecológicos vitales para el mantenimiento de la sociedad y de la naturaleza". Dichos "servicios" vienen dados por su contribución a la producción de agua limpia, oxígeno, la absorción de dióxido de carbono, la producción de barreras naturales que actúan eficazmente contra los efectos de inundaciones, mareas, huracanes, derrumbes y aludes. Las especies de vida silvestre actúan además como magníficos bioindicadores que predicen daños potenciales para la supervivencia humana y la calidad de la salud (Rubiano, 1989). El funcionamiento normal de las redes tróficas en los ecosistemas incluye plantas, herbívoros, carnívoros, omnívoros y descomponedores, todos ellos silvestres. La formación de suelo supone la interrelación entre la roca y los organismos vivos a través del ciclo de bio-geoelementos, en donde las plantas, hongos y bacterias, todos ellos de tipo silvestre, juegan el rol principal.

En cuanto a la dispersión de las plantas, bien sean domésticas o silvestres, en su mayor parte son polinizadas por insectos silvestres. Según datos recopilados por Jones (2010), en solo los Estados Unidos, el trabajo de los polinizadores le ahorra U\$ 57 mil millones de dólares al año, evidentes en la polinización de plantas de forraje y cultivos de alimentos. Para el neotrópico se han reportado casi 6000 especies de abejas que con sus visitas frecuentes a las flores se convierten en polinizadores eficientes, a diferencia de otros animales, que solo las visitan ocasionalmente (Nates-Parra, 2005). Para Colombia, dicha 
autora estima aproximadamente 1000 especies de abejas silvestres, agrupadas en 90 géneros y cinco familias. Otros autores (Freitas, 1997, 1998; González, 2000, Roubik, 1989) concuerdan en asignar a las abejas silvestres una mayor eficiencia en la polinización de plantas cultivadas y silvestres.

\subsubsection{Aspectos relacionados con la salud}

De mucho tiempo atrás es conocida la importancia de las plantas como medicina para el hombre. Sin ir más allá, China emplea cerca de 5000 plantas medicinales, México tiene registradas unas 4.500 y Colombia, con 2600 especies ocupa un tercer lugar (Muñetón, 2009). Sobra decir que la inmensa mayoría son plantas silvestres.

Además de su importancia en la producción de medicamentos, la vida silvestre brinda beneficios para la salud mental mediante interrelaciones con las personas hasta hace poco desconocidas. En 1984, el Doctor Edward O. Wilson, biólogo estadounidense, profesor emérito de la Universidad de Harvard, y coautor del concepto de "biodiversidad", acuñó el término "Biofilia" para describir un vínculo instintivo que existe entre los seres humanos y otras especies. Biofilia son "las conexiones que los seres humanos buscan inconscientemente con el resto de los seres vivos" (Kellert y Wilson, 1993). Según estos autores, nacemos con curiosidad y atracción hacia las otras criaturas vivas, impulsando el deseo innato de búsqueda, de ser pioneros, de explorar para sobrevivir. Al lado del concepto de "biofilia" aparece otro concepto no menos interesante: el "trastorno por déficit de naturaleza" introducido por Richard Louv (2008) en su libro "Last Child in the Woods: Saving Our Children from NatureDeficit Disorder". Según Louv, permanecer demasiado tiempo en el interior de la casa, tiene consecuencias negativas para los niños, comenzando con un incremento del Desorden de la hiperactividad del déficit de atención (ADHD), obesidad, limitaciones en la creatividad y curiosidad, deficiencia de vitamina $\mathrm{D}$, ignorancia de la flora y fauna local, pérdida del respeto por la naturaleza, disminución del sentido de comunidad, aumento del riesgo de trastornos mentales y agresividad, todo lo cual aumenta el riesgo de enfermedades cardiovasculares y diabetes (Louv, 2008). Un posible tratamiento a estos males consiste en interactuar directamente con la naturaleza, experiencia que, según el mencionado autor, reduce los riesgos de enfermedad física y mental, contribuye a la pérdida de sobrepeso, y a una autoestima más alta, especialmente en los jóvenes con discapacidades físicas. En su página personal (http://www:richardlouv.com/), Louv afirma que el aprendizaje presencial en la naturaleza, junto con la utilización de libros de texto, pueden mejorar las competencias en ciencias naturales y matemáticas.

\subsubsection{Importancia de la vida silvestre en la Salud Pública: Zoonosis}

Desde los años 70 se viene reportando en el mundo la reaparición de algunas enfermedades (dengue, tuberculosis, fiebre amarilla) y la aparición de otras nuevas (gripa aviar, enfermedad de las vacas locas, hendra, sida, etc.), cuya causa se atribuye a cambios en la biosfera, la globalización y a la intervención del hombre sobre los ecosistemas naturales (Herrero, 2008). Gran parte de estas enfermedades son zoonosis, es decir, enfermedades transmitidas por animales domésticos y silvestres al ser humano. Algunas de ellas, como la rabia o la toxoplasmosis que son transmitidas por mascotas domésticas tienen diagnóstico y tratamiento previsibles. Las zoonosis de fauna silvestre, por el contrario, debido a su diversidad y falta de información, suelen ser pandémicas y de tratamiento incierto. 
En Colombia, las principales zoonosis que utilizan reservorios silvestres en su ciclo epidemiológico son:

a) La leishmaniasis: mediante el marsupial Didelphis marsupialis y el roedor Proechimys canicollis ( Velez et al, 2001);

b) La tripanosomiasis americana o enfermedad de chagas: En un estudio realizado en el municipio de Amalfi Antioquia en el año 2000 se capturaron 33 animales silvestres pertenecientes, entre otros, a los géneros: Didelphis, Marteja, Marmosa, Hoplomys, Dasypus, Proechymis, Poechinus, Oryzomis, Philander y Rodentia, de los cuales un 20\% resultaron positivos para T. cruzi, mediante ELISA (Wolff et al, 2000 ).

c) La encefalitis equina venezolana: roedores pequeños de las especies Sigmodon, Proechimys, Zigodontomys y Hetromys y también marsupiales (Medina et al, 2000)

d) La rabia silvestre: principalmente por murciélagos hematófagos, no hematófagos y por zorros (ICA, 2004);

e) Gripa aviar: ante la amenaza de pandemia de la influenza aviar, se vienen desarrollando investigaciones en el papel de las aves silvestres en el ciclo epidemiológico (Acosta et al, 2009)

\subsection{Importancia per se de la vida silvestre}

Es un hecho indiscutible la aceptación universal de los derechos del hombre. La pregunta que se hace, desde diferentes ámbitos, es si tales derechos existen para el resto de los seres vivientes: "Conservation biology draws much of its ethical support from three primary ideas. The first is that all living creatures possess intrinsic valué. By logical extensión, assigning intrinsic valué to nonhuman creatures can lead to assigning to them certain rights, or at least treating them as if they did have rights" (Van Dyke, 2003, pp. 4).

En 1985, Bill Devall and George Sessions proponían en su libro Deep Ecology algunos principios relacionados con estos derechos, por ejemplo, los relacionados con la abundancia y diversidad de todas las formas vivientes. Según Nash (1989, en Spellemberg, 1992), el concepto sobre los "derechos de la naturaleza" proviene del concepto más antiguo de "Derechos Naturales": la idea de que ciertos segmentos de la sociedad, personas individuales, o incluso animales u objetos inanimados, poseen los derechos a continuar con su existencia en virtud del hecho de que ya existen.

Pero no se trata solamente del derecho a la existencia sino de todo lo que atañe a las necesidades a llenar para una calidad de vida silvestre "satisfactoria" (sensu los satisfactores de Jessup y Pulido, 1988). En un medio silvestre inalterado y/o protegido, v.gr. los parques nacionales y reservas, tales derechos son inherentes a la categorización del área protegida. El problema se presenta en áreas rurales, agrícolas o ganaderas en donde el Estado no garantiza la supervivencia ni la calidad del hábitat de la vida silvestre. De manera local, Egon et al (2005), establecieron tres criterios de calidad de vida silvestre para granjas de agricultura orgánica de Dinamarca, cuyo principal uso era el cultivo de cereales. Un primer criterio fue la cobertura de hierbas silvestres (incluyendo "malezas") puesto que 
los demás biotipos (árboles y arbustos) habían sido eliminados. Dichas malezas (y los factores que las controlan) resultaron ser el factor más decisivo para la calidad de flora y fauna silvestres, más cuando no había aplicación de pesticidas. Muchos estudios citados por los autores confirman la interrelación general entre la cobertura de malezas y la abundancia y diversidad de fauna, incluyendo artrópodos beneficiosos, escarabajos y arañas, todos ellos comida preferida para las aves propias de cultivos y barbechos, por ejemplo, alondras, avefrías, perdices grises, faisanes y mamíferos pequeños.

Otro criterio fue el área total (en porcentaje) de biotopos $^{3}$ no cultivados. En tierras agrícolas, la falta de cultivos en algunas áreas resulta ser un elemento esencial e indispensable para el establecimiento y mantenimiento de vegetación perenne y de la mayoría de las especies animales silvestres, particularmente aquellas de interés conservacionista.

Finalmente, se recurrió como criterio de calidad de vida silvestre a bioindicadores, en este caso a la mariposa azul común Polyommatus icarus cuyo aumento o declinación de sus poblaciones guarda estrecha relación con la destrucción del habitat, disturbios mecánicos, eutroficación del suelo, uso de pesticidas en campos cercanos y la reducción o suspensión de pastizales extensivos.

Según estos criterios, la supervivencia y calidad de la vida silvestre en áreas naturales dependería de la creación de reservas mientras que en el inmenso territorio restante (áreas rurales y urbanas) dependería de múltiples factores, relacionados unos con el manejo y sectorización de los cultivos o la ganadería (favorecimiento de hierbas silvestres, setos y barbechos) y otros, como se verá más adelante, con las políticas educativas e investigativas.

\section{CONCLUSIONES}

1. El presente estado del arte revela aspectos clave sobre las diferencias en la manera en que los norteamericanos y latinoamericanos concebimos la vida silvestre, la importancia que le damos, su irrupción y trascendencia en el sistema educativo e investigativo y su divulgación a través de la literatura científica y publicitaria. Al mismo tiempo plantea algunas preguntas relacionadas con la escasa trascendencia de la vida silvestre en la educación colombiana y la necesidad de futuras investigaciones. Si nos desplazamos a los albores del siglo XX, vemos como en los Estados Unidos fue decisivo el papel de los políticos, académicos y hombres pudientes, para el nacimiento de leyes para la protección de las especies silvestres y de los paisajes que las sustentan. Estos individuos inculcaron, a través de sus escritos, conferencias y gestiones administrativas, una conciencia ambiental y de pertenencia de los vastos recursos naturales de esta nación, no solo para las clases privilegiadas sino para todos los grupos sociales Decisiones históricas, como la creación de los primeros parques y reservas naturales del mundo, dan cuentan del inicio temprano de una cultura conservacionista y del desarrollo de una sensibilización hacia la vida silvestre

3 Se entiende como biotopo a un área de condiciones ambientales uniformes que provee espacio vital a un conjunto de flora y fauna. El biotopo es casi sinónimo del término hábitat con la diferencia que hábitat se refiere a las especies o poblaciones mientras que biotopo se refiere a las comunidades biológicas 
que aún persiste. Así, en 1871 se funda el primer Parque Nacional de los Estados Unidos (Yellowstone, con 898.300 hectáreas) mientras en Colombia, solo hasta 1960 se funda el primer Parque Nacional Natural (Cueva de los Guácharos) con tan solo 9.000 ha. Aunque no es claro el porqué de estas diferencias, más aún cuando Colombia tiene el privilegio de estar entra las cinco naciones con mayor biodiversidad del mundo, nos atrevemos a plantear dos hipótesis que merecen revisarse en futuras investigaciones: $1^{\circ}$ la influencia de una visión taxonómica de la naturaleza, principalmente en el área vegetal, promovida por la Expedición Botánica la cual centró sus investigaciones en la clasificación de plantas y animales dejando de lado las temáticas de ecología, conservación y sensibilización. $2^{\underline{0}}$ las dificultades que ha tenido la educación ambiental, y dentro de ella la educación sobre la vida silvestre, para incorporarse en el ámbito académico universitario. Ello debido, probablemente, a sus inicios y desarrollo dentro de un marco no formal propio de ONGs (UICN, UNESCO, etc.) por fuera del marco académico. La escasa presencia de la temática ambiental en gran parte de las carreras universitarias, particularmente de la educación en vida silvestre, avala esta hipótesis.

2. El concepto de vida silvestre se origina a comienzos del siglo $X X$ en Norteamérica y a partir de ahí ha tenido varias modificaciones en una perspectiva de menor a mayor complejidad. Partiendo de una acepción limitada a las "especies de caza deportiva" actualmente incluye las especies del mesocosmos (por ejemplo, los insectos) y del microcosmos (por ejemplo hongos y bacterias), haciendo énfasis en sus interrelaciones con el medio.

3. Aunque existe literatura sobre la importancia de la vida silvestre y sus derechos éticos, es muy poco lo que se ha investigado en Colombia sobre las interrelaciones sociales, culturales y económicas de la vida silvestre con el hombre. Hay un enorme campo de investigación por desarrollar en áreas de ciencias naturales tales como "bioindicadores de calidad de vida silvestre", "vida silvestre en centros urbanos", "vida silvestre en rastrojos y barbechos", "influencia de los pesticidas en cercas vivas y otros relictos de vida silvestre, "campos abandonados", "relaciones entre la cobertura de malezas silvestre y la diversidad de fauna silvestre" etc., etc., y en áreas de ciencias de la educación tales como "actitudes sobre la vida silvestre en estudiantes de educación básica, secundaria y universitaria", "concepciones sobre la vida silvestre en varios ámbitos educativos", "modelos didácticos para la educación en vida silvestre", etc., etc.

4. Un problema no menos importante surge al observar la legislación sobre vida silvestre en Colombia en donde la acepción de lo que habría que conservar y proteger se refiere únicamente a los reinos animal y vegetal dejando por fuera los reinos o dominios restantes (protistos, hongos y procariotes) así como sus habitats. Dicha concepción de vida silvestre no ha tenido ninguna reformulación a partir de su publicación en 1974 en el Código de los Recursos Naturales.

5. Cabe destacar la importancia de la vida silvestre en la prestación de servicios ambientales, principalmente en su papel trascendental dentro del ciclo del agua a través de especies acumuladoras -tipo Sphagnum- y en general de las comunidades de páramo y bosque andino que suplen los pequeños y grandes acueductos. Otros servicios como el aporte de oxigeno, consumo de $\mathrm{CO} 2$, control de la erosión, regulación del clima, reservorio de especies útiles para hibridación, importancia para la información estética, espiritual, 
histórica, cultural y educacional, etc., (ver Márquez, 1996) se han investigado muy poco en Colombia.

6. El concepto de vida silvestre tiene un enorme potencial para las políticas ambientales, educativas, sociales y económicas. Su función para el desarrollo de la vida humana abarca roles científicos, ecológicos, culturales, pedagógicos, recreativos, religiosos, artísticos, éticos y estéticos, donde la escala de valores que tienen las personas influye decisivamente en las dos pautas a seguir, esto es, hacia la preservación de este componente del planeta (bien sea que se asuma como un derecho ético per se o como un recurso esencial para la supervivencia humana) o hacia su destrucción y desaparición. Cuando hablamos de vida silvestre estamos implicando no solo los aspectos formales sobre biología o taxonomía sino la manera como abordamos esta concepción en una perspectiva social, histórica, ética y de actitudes y valores. Y es precisamente a la sociedad, a través de su estamento educativo, a quien corresponde emprender un nuevo tipo de relación con la vida silvestre; en palabras de Aldo Leopold (Leopold, 1949): "Una ética de la tierra no puede, por supuesto, evitar la alteración, el manejo y el uso de esos "recursos", pero sí afirma su derecho a su continua existencia y, por lo menos en ciertos lugares, a que su existencia continúe en un estado natural. En suma, una ética de la tierra cambia el papel del Homo sapiens: de conquistador de la comunidad de la tierra al de simple miembro y ciudadano de ella. Esto implica el respeto por sus compañeros-miembros y también el respeto por la comunidad como tal".

\section{BIBLIOGRAFIA}

Acosta O., C. A. Guerrero, J. A. Cortés. (2009). Aspectos básicos, clínicos y epidemiológicos de la influenza. Revista Facultad de Medicina de la Universidad Nacional de Colombia. Vol.57 No.2. Bogotá Jan/mar.

Alaska State Department of Education. (1989). Outdoor Recreotion and Wildlife Management Resources. Developed by the Div. of Adult and Vocational Education. 294p. Recuperado el 28 de marzo de 2010 de http://www.eric.ed.gov/ERICWebPortal/search/detailmini.jsp?_nfpb=true\&_\&ERICExtSear ch_SearchValue_0=ED322355\&ERICExtSearch_SearchType_0=no\&accno=ED322355

Baker, William L. (2006). Fire and Restoration of Sagebrush Ecosystems. Wildlife Society Bulletin, Volume 34, Issue 1 (March 2006) pp. 177-185

Begon, M., J. L. Harper y C.R. Townsed. (1995). Ecología. Ediciones Omega S.A. Barcelona, España.

Berle Meter (1987). The Audubon view. En: Audubon Vol. 89, № 2, pp. 4

Blackstone, Wm. (1971). Commentaries on the Laws of England. Facsimile of the first edition of 1765-1769. Chicago: University of Chicago Press.

Camero Luis A. y Clara M. Sánchez. (2008). Libro de Actividades. Grupo Editorial Norma.

Calderón, Gina G., Luis A. Camero, Gladis M. García, Patricia Lugo, Clara M. Sánchez. (2008a). Viajeros 4. Ciencias. Grupo Editorial Norma. 
Calderón, Gina G., Luis A. Camero, Gladis M. García, Patricia Lugo, Clara M. Sánchez. (2008b). Viajeros 5. Ciencias. Grupo Editorial Norma.

Clay, Schoenfeld. (1976). Environmental Education and wildlife conservation. Council on Environmental Quality, Washington. 34p.; Paper presented at the National Syaposium on wildlife in America (Washington, D.C., september 29-0ctober).

Código Nacional de Recursos Naturales Renovables y de Protección al Medio Ambiente Decreto 2811 DE 1974 (diciembre 18) Diario Oficial No 34.243, del 27 de enero de 1975. (1975). Recuperado en mayo de 2010 de http://pwp.etb.net.co/mopazog/CRNR.pdf

Corporación Club de Caza y Tiro Los Patojos. (2010). Recuperado el 11 de agosto de 2010 de: http://clubdetirolospatojos.blogspot.com/

Correa de Restrepo, M. (2005). Departamento de Biología, su Memoria Histórica. Acta Biológica Colombiana 10(1): 45-66.

Crawford, John A. (1976). Nongame Wildlife: The Role of the University. Wildlife Society Bulletin, Vol. 4, No. 3 (Autumn, 1976), pp. 116-119. Published by: Allen Press.

Curtis H. y N. S. Barnes. (1993). Biología. Editorial Médica Panamericana, Buenos Aires, Argentina.

Chinery, Michael. (1979). Guía práctica ilustrada para los amantes de la naturaleza : cómo observar, estudiar, coleccionar, conservar y explorar la fauna y la flora de la ciudad y del campo con fascinantes trabajos y experimentos. Ed. Blume. Barcelona

Devall, W. and G. Sessions. (1985). Deep Ecology: Living As if Nature Mattered Salt Lake City. Gibbs M. Smith, Inc.

Diccionario Ilustrado Océano de la Lengua Española. (1997). Océano Grupo Editorial S.A. Barcelona.

Diccionario Thesaurus Ingles-Inglés. (2010). Recuperado el 14 de febrero de 2010 de http://www.merriam-webster.com/thesaurus/wildlife?show=0\&t=1305219397

Diccionario Oxford Español-Inglés Inglés-Español (1994). Oxford University Press. Oxford, New York, Madrid.

Díaz-Martin Diego. (1993)¿Cuánto vale la vida silvestre? Revista La Era Agrícola № 16,

Eastmond J Nicholls. (1975). An assessment of Educational needs for the Department of wildlife science. Utah state Univ., Logan, Div of Instruccional Development

Egon Noe, Niels Halberg and Jens Reddersen. (2005). Indicators of biodiversity and conservational wildlife quality on Danish organic farms for use in farm management: A multidisciplinary approach to indicator development and testing. Journal of Agricultural and 
Environmental Ethics. pp. 383-414. Springer.

Elbroch Mark. (2003). Mammal Tracks E Sign: A Guide to North American Species. Stackpole Books. Ritter Road Mechanicsburg.

El-Hani Charbel Niño. (2008). Theory-based approaches to the concept of life. Journal of Biological Education Volume 42 Number 4.

Freitas B. (1997). Number and distribution of cashew (Anacardium occidentale) pollen grains on the bodies of its pollinators, Apis mellifera and Centris tarsata. Journal of Apiculture Research 36(1):15-22.

Freitas B. (1998). Importancia relativa de Apis mellifera e outras Espécies de Abelhas na polinização de culturas agrícolas.In Encontro sobre abelhas $(3, .1998)$. Anais Ribeirão Preto, BR p.10-20. $1998 \mathrm{~b}$

Fulton David C., Kevin Skerl, Erin M. Shank, and David W. Lime. (2004). Beliefs and attitudes toward lethal management of deer in Cuyahoga Valley National Park. Wildlife Society Bulletin, Volume 32, Issue 4 (December 2004) pp. 1166-1176.

García Díaz, J. Eduardo. (1994). El conocimiento escolar como proceso evolutivo: aplicación al conocimiento de nociones ecológicas. Investigación en la Escuela, № 23.

Genevieve, Cousins and Bonnie Kae Smith. (1968). Free and Inexpensive Materials for Teaching Conservation: Wildlife and Fish section. Natchitoches Parish School Borrad. Documentos Eric.

Glavin, Terry. (2007). The Sixth Extinction: Journeys among the Lost and Left Behind (New York: St. Martin's Press). En Callicott J. B. 2008. ¿Cuál "Naturaleza Virgen" en los Ecosistemas de Frontera? Environmental Ethics, Vol. 30. Fall 2008.

González V. H. (2000). Las abejas silvestres de Colombia: por qué y como conservarlas. Acta Biológica Colombiana. 5(1):5-37.

Gran diccionario de la lengua española Larousse .(2009). Larousse Editorial S.L. España.

Havell Edition of Audubon Prints. (2010) Guide to the art prints of John James Audubon - Birds of America artist. Recuperado en septiembre de 2010 de http://www.audubonprints.com/havell-audubon.htmlaudubon)

Hernbrode, William R., Ed. (1978). Multidisciplinary Wildlife Teaching Activities.

Information Reference Center (ERIC/IRC), The Ohio State University. Columbus, Ohio.

Herrero Uribe, L. (2008). La salud integral incluye la vida silvestre. Boletín CIENTEC, Universidad de Costa Rica. San José, Costa Rica. Publicado en el diario "La Nación". $\begin{array}{lllll}\text { Recuperado en } & \text { mayo de }\end{array}$ http://www.cientec.or.cr/mhonarc/boletincientec/doc/msg00671.shtml. 29 de sept. 2008 
Holden E. (1980). La felicidad de vivir con la naturaleza. Reproducción facsímil del diario de una naturalista a lo largo del año 1906. Editorial Blume. Barcelona

Holden E. (1990). Diario Ilustrado sobre la naturaleza. Reproducción facsími de la edición de 1905. Ediciones Folio S.A. Barcelona

Hornaday William T. (1913). Our vanishing wild life: its extermination and preservation. With maps and illustrations. Charles Scribner's Sons. New York. Recuperado el 11 de mayo de 2010 de Project Gutenberg's: http://www.gutenberg.org/files/13249/13249-h/13249-h.htm

Hurlingham Club, Argentina. (2010). recuperado el 11 de agosto de 2010 de: http://www.webhghamclub.natus.com.ar/

ICA. (2004). Manual de procedimientos control y erradicación de riesgos zoosanitarios. Rabia silvestre. Resolución № 0033361 de 30 de diciembre 2004. Recuperado el 2 de septiembre de 2010 de http:/www.ica.gov.co/getdoc/bd53457f-f7a1-4928-a932-3198006af1ff/MP-RS-00Generalidades.aspx

Instituto de Investigación de Recursos Biologicos Alexander Von Humboldt. Enero (1999). Biosíntesis, Boletin No. 11. Hacia la Conservación de las Especies Amenazadas de Colombia. Recuperado en agosto 11 de 2010 de http://www.humboldt.org.co/download/bol11.pdf

Jardín Botánico José Celestino Mutis de Bogotá, Universidad Nacional de Colombia. (2010). Las maticas del monte. Bogotá, D.C.

Jessup, Margie y R. Pulido. (1998). Los estudios de Calidad de Vida: Alternativa de Educación basada en la Investigación. Revista TEA. Técne, Episteme y Didaxis. Facultad de ciencia y educación. Universidad Pedagógica Nacional. Bogotá. (4). 1998.

Johnson Jenny. (1997-2008). Animal Tracks and Signs: Over 400 Animals from Big Cats to Backyard Birds by 1997-2010. National Geographic Society

JONES Jeanne. (2010). The Human-Animal Bond Lecture Series at Mississippi State University. MS State FWRC - Wildlife and Fisheries. Recuperado en agosto de 2010 de http://www.msite.ext.msstate.edu/mediasite/Viewer/?peid=a1c8d425320a4bdcac7067249909 af4c. 15 de febrero de 2010

Journals: Advanced Search. (2010). Wild Life Society. Recuperado el 22 de abril de 2010 de http://www.wildlifejournals.org/perlserv/

?anywhere=plants\&anywhere_boolean=ANY\&total_hits=0\&request=search-

simple\&searchtype $=$ simple\&hits_per_page $=10 \&$ previous_hit $=20 \&$ sort $=$ relevance\& $x=10 \& y=$ $5 \#$ results.

Kawasaki C. S. y Ch. N. El-Hani. (2002). Uma análise das definições de vida encontradas em livros didáticos de biología do ensino médio. VIII Encontro "Perspectivas do Ensino de Biologia". Recuperado en febrero 10 de 2010 de http://www.modelab.ufes.br/xioste/papers/xioste_paper012.pdf 
Kellert S. R and E. O Wilson (Eds.). (1993). The Biophilia hipótesis. Island Press. USA.

Kellert S. R. (1986). Social and perceptual factors in the preservation of animal species. Pages 50-73 in B. G. Norton, editor. The preservation of species: The value of biological diversity. Princeton University Press, Princeton, New Jersey.

Kirby Chester. (1933). The English Game Law System. The American Historical Review, Vol. 38, No. 2 (Jan., 1933), pp. 240-262. Published by: The University of Chicago Press on behalf of the American Historical Association. Stable URL: http://www.jstor.org/stable/1838294. Accessed: 17/10/2010 09:51Your

Leedy, Daniel L. (1978). Planning for Wildlife in Cities and Suburbs. Urban wildlife Research Center, Inc., Ellicott City. American Society of Planning Officials, Chicago. Fish and Wildlife Service (Dept. of Interior). Washington, D.C. Documentos Eric

Leopold, A. (1966). A Sand County almanac with essays on conservation from Round River New York: Sierra Club/Ballantine. En Fred Van Dyke. Conservation Biology: Foundations, concepts, aplications. Mc Graw Hill. 2003. N.Y.

Leopold, Aldo. (1949). A Sand County Almanac. Oxford University Press. New York. En Rozzi, Ricardo. 2007. De las ciencias ecológicas a la ética ambiental. Revista Chilena de Historia Natural 80: 521-534

Ley N 7317 y Ley de Conservación de la Vida Silvestre del 30 de octubre de 1992. Costa Rica. (1992). Recuperada el 29 de mayo de 2010 de http://www.iica.int/Esp/organizacion/LTGC/Ambiental/Document

Ley General de vida silvestre. (2000). Nueva Ley publicada en el Diario Oficial de la Federación el 3 de julio de 2000. Texto Vigente: Última reforma publicada DOF 14-10-2008 MEXICO. Recuperada en enero de 2010 de http://www.diputados.gob.mx/LeyesBiblio/pdf/146.pdf

Ley Forestal y de Conservación de Áreas Naturales y Vida Silvestre. Ecuador. Codificación 17, Registro Oficial Suplemento 418 de 10 de Septiembre del 2004. Recuperado el 12 de mayo de 2011 de http://www.mineriaecuador.com/Download/ley_forestal.pdf

Louv Richard. (2008). Last Child in the Woods: Saving Our Children from Nature-Deficit Disorder. Algonquin Books. 390 p.

Lueck Dean. 1989. The Economic Nature of Wildlife Law. The Journal of Legal Studies, Vol. 18, No. 2, pp. 291-324. Published by: The University of Chicago Press. Stable URL: http://www.jstor.org/stable/3085623. Accessed: 17/10/2010 10:07.

Maldonado Adriana A. (2004). Revisión del concepto biológico desarrollado en la legislación colombiana relacionada con la fauna silvestre vertebrada terrestre. Monografía para optar al título de bióloga. Universidad Nacional de Colombia, Facultad de Ciencias, Departamento de Biología. Bogotá, D.C.

Margalef, R. (1995). Ecología. Ediciones Omega S.A. Barcelona, España. 
Márquez Germán C. (2004). Transformación de ecosistemas y condiciones de vida en Colombia. Tesis de Doctorado. Universidad de los Andes, Instituto de Ciencias Ambientales y Ecologicas ICAE, Postgrado En Ecología Tropical. Mérida, Venezuela.

Márquez Germán C. (1996). Ecosistemas Estratégicos y otros estudios de Ecología Ambiental. Ediciones FONDO FEN COLOMBIA. Primera Edición, Bogotá 1996. 211 pp.

Medina, G, R. Salas, J. de Siger, E. Jaimes e I. Matheus. (2000). Virus de Encefalitis Equina Venezolana en el municipio Catatumbo del Estado Zulia. 1996-1997.II. Aislamiento y caracterización. Veterinaria Trop. 25(2):237-255.

Miller, Karl V and James H. Miller. (2004). Forestry herbicide influences on biodiversity and wildlife habitat in southern forests. Wildlife Society Bulletin Volume 32, Issue 4 (December 2004) pp. 1049-1060

Ministerio del Medio Ambiente del Ecuador. (2004). 1. El concepto de vida silvestre. Recuperado en mayo de 2010 de http://www.ambiente.gov.ec/contenido.php?cd=374

Ministerio del Medio Ambiente. (2002). Resolución 584 de 2002: Por la cual se declaran las especies silvestres que se encuentran amenazadas en el territorio nacional y se adoptan otras disposiciones. Recuperado en agosto 12 de 2010 de http://www.alcaldiabogota.gov.co/sisjur/normas/Norma1.jsp?i=6427

Mitchell John G. (1987). A man called bird. En: Audubon magazine. Vol. 89, № 2.

Morning Heart. (2010). Edith Holden: 1871-1920. Recuperado en septiembre de 2010 de earth.org/ARTISTNATURALISTS/AN_Holden.html. On Line

Muñetón Pérez Patricia. (2009). Plantas medicinales: un complemento vital para la salud de los mexicanos. Revista Digital Universitaria. UNAM. Vol. 10 № 9.

Nash R. F. (1989). The rights of nature. En: Spellerberg, Ian. F. 1992. Evaluation and assessment for conservation. Ecological guidelines for determining priorities for nature conservation. Chapman \& Hall. London

Nates-Parra G. (2005). Abejas silvestres y polinización. Manejo integrado de plagas y Agroecología (Costa Rica) № 75 p. 7 - 20

Odum, E. P. (1987. Ecología. Nueva Editorial Interamericana, México, D.F.

Owen Oliver. (2000). Conservación de Recursos Naturales. Editorial Pax, Mexico. Segunda edición

Project Wild. (1986). Elementary Activity Guide. The Western Regional Environmental Education Council. Printed in the USA. 
Restrepo, Olga Forero. (1986) "El tránsito de la Historia Natural a la Biología en Colombia". Ciencia, Tecnología y Desarrollo. (Bogotá), 10 (3/4): 181-275, jul.-dic.

Roubik, D. W. (1989). Ecology and Natural History of tropical Bees. Cambridge Universty Press. 514.p. 1989.

Rubiano L. J. (1989). Líquenes como indicadores de contaminación en Ia Termoeléctrica de Zipaquirá y el Complejo Industrial de Betania, Cundinamarca. Acta Biológica Col.. Vol. 1 No. 4. Bogotá, D. E.

Serie Libros Rojos de Especies Amenazadas de Colombia. (2010). Recuperado en marzo de 2010 de http://www.humboldt.org.co/conservacion/libros_rojos/

Spellerberg, Ian. F. (1992). Evaluation and assessment for conservation. Ecological guidelines for determining priorities for nature conservation. Chapman \& Hall. London.

Solomon E., L. Martin. (2008). Biología. Octava Edicion Interamericana Mcgraw Hill 2008

Smith Richard P. (1982). Animal Tracks and Signs of North America: Recognize \& Interpret Wildlife Clues . Stackpole books.

Sutton, D. B. y N. P. Harmon. (1977). Fundamentos de Ecología. Editorial Limusa, Mexico.

The Wildlife Society. (2010). Recuperado en septiembre de 2010 de http://joomla.wildlife.org/

The Reviewer's List: Ten Most Infuential Environmental Books of the 20th Century. (2010). Recuperado en agosto de 2010 de http://www.ronwatters.com/BkTheRev.htm

Torres, Maritza C. (1998). La Educación Ambiental: una estrategia flexible, un proceso y unos propósitos en permanente construcción. Revista Iberoamericana de Educación Número 16 Educación Ambiental y Formación: Proyectos y Experiencias.

T. Roosevelt Association. (2010). Life of Theodore Rooselvelt. Recuperado en septiembre de 2010 de http://www.theodoreroosevelt.org/life/timeline.htm. 2010 On Line

Tunstall, Margaret, Jennifer Kier, Cheryl Dixon, Sara Bradley, Elenor Hodges and Sharon Levely. (1998). Nature's Web: Caring for the land. National wildife week educators's guide. National Wildlife Federation Vienna VA. Documentos Eric.

UICN, the International Union for Conservation of Nature. (2008). Wildlife in a changing World. An analysis of the 2008 IUCN Red List of Threatened Species. Recuperado el 11 de agosto de 2010 de http://data.iucn.org/dbtw-wpd/edocs/RL-2009-001.pdf

Uniguru: The study abroad site for indian students, (2010). Recuperado en septiembre de 2010 de http://www.uniguru.com/studyabroad/university-courses/wildlife-conservationprotection-postgraduate-courses/programs/category/qa.911/browseid/7096.html 
U.S. Fish and Wildlife Service. Southeast Region. (2010a). Federal Aid Division -- The Pittman-Robertson Federal Aid in Wildlife Restoration Act. Recuperado el 17 de octubre de 2010 de http://www.fws.gov/southeast/federalaid/pittmanrobertson.html.

U.S. Fish and Wildlife Service. (2010b). The Federal Duck Stamp Program. Recuperado el 17 de octubre de 2010 de http://www.fws.gov/duckstamps/info/stamps/stampinfo.htm

Van Dyke, Fred. (2003). Conservation Biology: Foundations, concepts, aplications. Mc Graw Hill.

Velez, I., D. E. Hendrickx, S. M. Robledo, S. del Pilar Agudelo.(2001). Leishmaniosis cutánea en Colombia y género. Cad. Saúde Pública, Rio de Janeiro, 17(1):171-180.

Vida Silvestre Colombia. (2006). Protejamos la Naturaleza, es la fuente de la vida. Recuperado en abril de 2010 de http://vidasilvestrecolombia.blogspot.com/. 2006 En Línea

Ville, C. A., Solomon, E. P. y Davis P. W. (1992). Biología. Interamericana. México.

Weidensaul, Scott. (2005). Return to Wild America: A Yearlong Search for the Continent's Natural Soul. North Point Press. New York

Westervelt Miriam O. and Lynn Llewellyn. (1985). Youth and Wildlife: The Beliefs and Behaviors of Fifth and Sixth Grade Students Regarding Non-Domestic Animals. Fish and Wildlife Service (Dept. of Interior), Washington, D.C.

Wisdom, Michael J., Martin Vavra, Jennifer M. Boyd, Miles A. Hemstrom, Alan A. Ager, and Bruce K. Johnson. (2006). Understanding Ungulate Herbivory-Episodic Disturbance Effects on Vegetation Dynamics: Knowledge Gaps and Management Needs. Wildlife Society Bulletin

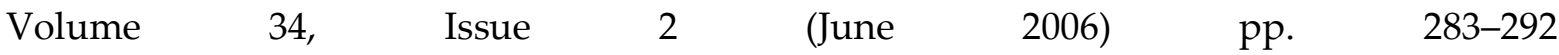

Wolff, Martha, Diana Castillo y J. Arboleda. (2000). Estudio eco-epidemiológico de la tripanosomiasis americana en el municipio de Amalfi (Antioquia). Iatreia, Vol 13, No 2. 